This is the peer reviewed version of the following article: PATAI'S Chemistry of Functional Groups 2018, Vinylation and Alkynylation, which has been published in final form at https://onlinelibrary.wiley.com/doi/

full/10.1002/9780470682531.pat0951. This article may be used for non-commercial purposes in accordance With WileyVCH Terms and Conditions for self-archiving

\title{
Alkynylations and Vinylations
}

Durga Prasad Hari, ${ }^{a}$ Stefano Nicolai ${ }^{\mathrm{a}}$ and Jerome Waser*a

${ }^{a}$ Laboratory of Catalysis and Organic Synthesis, Ecole Polytechnique Fédérale de Lausanne, EPFL SB ISIC

LCSO, BCH 4306, 1015 Lausanne, Switzerland, jerome.waser@epfl.ch

\begin{abstract}
Absract:
Alkynes and alkenes are important building blocks in synthetic organic chemistry and related domains. Therefore, unceasing efforts have been invested to develop new methods to introduce these valuable functional groups. Traditionally, most alkynylation and alkenylation reactions have relied on the use of olefins and acetylenes as nucleophilic reacting species, limiting the accessible structural diversity. The discovery of the unique properties of hypervalent iodine has more recently significantly broadened the scope of electrophilic ethynylation and vinylation reactions. Alkynyl and alkenyl iodonium salts were first recognized as powerful reagents to install electrophilic acetylenes and olefins onto nucleophilic substrates under mild conditions. Their low stability has however narrowed the area of their applications. Since 2009, more stable cyclic benziodoxol(on)e reagents have shown their superiority as effective electrophilic alkynylating and alkenylating reagents in numerous metal-free and metal-catalyzed olefination and ethynylation reactions of carbon centered nucleophiles, radicals, and heteroatom nucleophiles. In this chapter, an overview of the progress in the field is presented, including a short summary of pioneering works, followed by a more in-depth description of recent results.
\end{abstract}

Keywords: Alkynes $\cdot$ Alkenes $\cdot$ Alkynyliodonium salts $\cdot$ Alkenyliodonium salts $\cdot$ Ethynylbenziodoxol(on)es $($ EBX) $\cdot$ Vinylbenziodoxolones (VBX) 
I. INTRODUCTION

II. ALKYNYLATION REACTIONS

A. Alkynylation of C-Nucleophiles

1. Base-mediated alkynylation reactions

2. Transition metal-catalyzed alkynylation reactions

3. Alkynylation of carbon radicals

4. Alkynylation as part of Domino reactions

B. Alkynylation of Heteroatoms

1. Oxygen

2. Nitrogen

3. Sulfur

4. Phosphorous

5. Metals

III. ALKENYLATION REACTIONS

A. Synthesis and Stability of Hypervalent Iodine Alkenylation Reagents

B. Alkenylation of Heteroatoms

C. Alkylidene Carbenes

D. Alkenylation of C-Nucleophiles

IV. CONCLUSIONS 


\section{INTRODUCTION}

Multiple carbon-carbon bonds are highly valuable in organic chemistry. While they are relatively stable under many conditions, their easy functionalization makes them of great utility from the synthetic point of view. A large variety of reactions are indeed available that enable the transformation of both alkynes and alkenes into other useful functionalities. In addition, the unique chemical and physical properties of alkynes have attracted growing attention in neighboring scientific domains, such as material sciences and biological chemistry ${ }^{1}$. The pivotal role alkynes and alkenes play in both synthetic and applied fields has prompted unceasing efforts to access them with high efficiency and flexibility.

Historically, the most common alkynylation and alkenylation processes have been based on the transfer of nucleophilic $\mathrm{C}-\mathrm{C}$ multiple bond synthons (Scheme 1). The sp-hybridization confers a highly acidic character to the terminal $\mathrm{C}-\mathrm{H}$ bond, and therefore provides a facile access to acetylide anions. Accordingly, the addition of acetylides to carbonyl substrates ${ }^{2}$ and the Sonogashira reaction ${ }^{3}$ have become well established routine procedures. On the other side, while olefins are not as easily deprotonated, a large variety of nucleophilic reagents are readily accessible in the form of alkenyl magnesium, zinc, boron, silicon, or tin derivatives for the addition to electrophiles through metal catalysis ${ }^{4}$.

The reactions operating through the transfer of nucleophilic $\mathrm{C}-\mathrm{C}$ multiple bond synthons are well appreciated for their reliability and high efficiency. Nevertheless, the great abundance of nucleophiles in synthetic chemistry as well as in applied sciences raised interest into the reversed approach: the addition of nucleophiles to electrophilic alkynyl and alkenyl reagents. While this kind of transformations would be highly desirable, they are often challenging, as they demand the reversal of reactivity (Umpolung) of the sp or $\mathrm{sp}^{2}$ bonds of alkynes and alkenes. In fact, most reactions with electron-deficient alkenes and alkynes result in simple addition to the $\pi$-system and loss of one multiple bond. It is therefore not surprising that the use of electrophilic alkynylation and vinylation remained long underdeveloped ${ }^{5-7}$, and only during the last decades major progress has been made in the development of this kind of transformations.

The exceptional properties of hypervalent iodine reagents have attracted the interest of synthetic chemists since their discovery ${ }^{8}$. In particular, the exquisite ability of these compounds to act as electrophilic synthons of normally nucleophilic groups has allowed them to gain a central role in the area of electrophilic alkynylation and alkenylation reactions (Scheme 1). First reported by Beringer in $1965^{9}$ and then studied intensively in the late 1980s, alkynyl- and alkenyl(aryl)iodonium salts are especially suited for the transfer of acetylenes and olefins onto diverse nucleophiles ${ }^{10-12}$. During the last decade, the enhanced stability and selectivity displayed by cyclic alkynyl iodanes, in particular ethynyl 1,2-benziodoxol-3(1H)-ones and 1,2-benziodoxoles (EBX), have 
led to a renewed interest in the research on hypervalent iodine mediated electrophilic alkynylation ${ }^{13}$. While investigations on electrophilic vinylation have progressed at a relatively slower pace, the use of vinyl(aryl)iodonium salts also has undergone a revival during the last few years, and further developments may be promoted by the recent advances in the synthesis of vinylbenziodoxoles ${ }^{14}$.

Key to the success encountered by alkynyl and alkenyl hypervalent iodine reagents is their exceptional reactivity that make them superior to less reactive reagents like halides ${ }^{15}$ and sulfones ${ }^{16-20}$. Because of the great nucleofugality of the aryliodonio group ${ }^{21}$, these compounds are highly activated species, whose reactivity can be adjusted by tuning the trans effect exerted by the substituents on the hypervalent iodine center ${ }^{22,23}$. Interestingly, this behavior is reminiscent of the properties of transition metal complexes. Further advantages derive from the higher stability and the lower toxicity they exhibit compared to organometallic compounds such as organolead derivatives ${ }^{24,25}$. Enhanced stability can be in particular observed with cyclic benziodoxol(on)e reagents. In these compounds, additional stabilization originates from the bridging of the apical and the equatorial ligands at the hypervalent center through a five-membered ring ${ }^{26}$. This also results in a better overlap of the non-bonding orbitals of the iodine atom with the $\pi$-orbitals of the aromatic ring in the equatorial position. At the same time, because of the cyclic structure, the orientation of the lone pairs on the oxygen atom are fixed in space and the reductive elimination from III becomes a higher energy process, therefore preventing the isomerization to the more stable ether isomer ${ }^{27}$. Finally, as a strongly nucleophilic oxygen ligand can be included in the ring, an important trans effect is induced ${ }^{22,23}$ that leads to further modulation of the reactivity when compared to iodonium salts.

The present chapter describes the recent achievements in the field of electrophilic alkynylation and alkenylation reactions though the use of hypervalent iodine reagents. After summarizing the most important works up to the last review in this research area ${ }^{28}$, a more in-depth description will be then provided of the most recent results until March 2017. The attention will be initially focused on electrophilic alkynylation reactions (Section II). In particular, the alkynylation of C-nucleophiles will be treated first, followed by acetylene transfer onto heteroatoms. Finally, the works involving hypervalent iodine reagents for alkenylation reactions will be summarized (Section III). The focus is on transformations using well-defined hypervalent iodine reagents for alkynylation and vinylation.

\section{ALKYNYLATION REACTIONS}

Over five decades, the interest in the unique properties of alkynyl hypervalent iodine compounds has led to significant efforts to develop new approaches for the synthesis of these compounds. The establishment of 
robust, straightforward, and usually scalable preparative methods for both iodonium salts and cyclic iodane reagents has certainly contributed to the rapid expansion of their applications during the last few years.

First reported in $1965^{9}$, alkynyl(aryl)iodonium salts have acquired an important role in organic chemistry as useful and versatile synthetic tools. Their applications are not limited to electrophilic alkynylation but also include Michael-type conjugate additions, cyclization, and cycloaddition reactions ${ }^{10,29}$. Moreover, they can be used as starting materials for the preparation of vinyl(aryl)iodonium salts (Section III). The synthesis of these compounds, which has been already extensively reviewed ${ }^{10}$, generally involves the reaction of an acetylide source with a suitable hypervalent iodine reagent (Scheme 2.1). A common approach consists in reacting silyl acetylenes with iodosobenzene $\mathrm{e}^{30-32}$ or (diacetoxy)iodobenzene ${ }^{31}$ in the presence of a Lewis acid and a metal salt. A broader scope can be achieved by combining cyano(phenyl)iodonium triflate with alkynyl stannanes ${ }^{33}$. More recently, the preparation of alkynyl(aryl)iodonium salts has also been reported through a practical one-pot oxidation/alkynylation method, in which iodobenzene is combined with ethynyl boronic esters in the presence of meta-chloroperoxybenzoic acid $(m \text {-CPBA })^{34}$.

As previously mentioned (Section I), the enhanced stability of ethynyl benziodoxol(on)es has recently established them as valuable alternatives to iodonium salts ${ }^{35}$. The most common procedure for the synthesis of ethynyl benziodoxolones $\mathbf{3}$ was initially developed by Ochiai and coworkers and later improved by the research group of Zhdankin ${ }^{36,37}$. As illustrated in Scheme 2.2, hydroxybenziodoxolone 2 (generated through the oxidation of 2-iodobenzoic acid $\mathbf{1}$ ) is first activated with trimethylsilyl triflate and then reacted with trimethylsilyl acetylenes. An adjustment of the work-up conditions reported by Brand and Waser allowed to adapt this protocol to the reproducible synthesis of multi-gram amounts of such compounds ${ }^{38}$. This robust and easily scalable method performs especially well for the preparation of silyl and aryl substituted EBX, with broad tolerance toward the substituents on the benziodoxolone core. A faster procedure was reported by Bouma and Olofsson in $2012^{34}$, who developed a one-pot protocol directly from 2-iodobenzoic 1 acid via in situ oxidation of the latter with $m$-CPBA, reaction with the corresponding alkynyl boronic ester and quench with sodium bicarbonate. This method enables access to alkyl-, aryl-, and silyl-substituted EBX. In a similar way, alkynyl benziodoxoles 8 and 9 could be generated from the corresponding hydroxybenziodoxoles 6 and 7, which were synthesized through a two-step oxidation procedure from alcohols $\mathbf{4}$ and $\mathbf{5}$. The procedure established by Zhdankin could be effectively extended to hydroxy hexafluorodimethylbenziodoxole 6 for the preparation of ethynyl bis(trifluoromethyl)benziodoxoles $\mathbf{8}^{37}$. By contrast, Waser and coworkers demonstrated that a more reactive lithium acetylide was necessary for the synthesis of dimethyl-substituted ethynyl benziodoxole reagents 9 from intermediate $7^{39}$.

A. Alkynylation of C-Nucleophiles 


\section{Base-mediated alkynylation reactions.}

The great potential of hypervalent iodine reagents for electrophilic acetylene transfer could be first demonstrated for the alkynylation of enolate nucleophiles. Groundbreaking reports in this area focused on the alkynylation of diketones using alkynyl(aryl)iodonium salts. After a seminal work published by Beringer and Galton already in $1965^{9}$, Ochiai and coworkers explored in depth this transformation by treating 2 -substituted indanediones such as $\mathbf{1 0}$ with different alkynyl iodonium tetrafluoroborates $\mathbf{1 1}$ in the presence of strong bases (Scheme 3$)^{40}$. They discovered that the outcome of the process depended on the R-group on the ethynyl moiety: the alkynylation product $\mathbf{1 2}$ was obtained with a phenyl group, whereas the formation of cyclopentene derivatives like 13 was observed with alkyl groups. Based on these findings, the authors formulated a mechanistic hypothesis: In contrast to most reactions of nucleophiles with hypervalent iodine reagents, the enolate would not attack on the iodine atom, but would instead undergo a Michael-type addition onto the $\mathrm{C} \equiv \mathrm{C}$ triple bond. Elimination of iodobenzene from the resulting intermediate $\mathbf{1 4}$ would then lead to the formation alkylidene carbene $\mathbf{1 5}$. The fate of the latter is finally determined by the migratory aptitude of the R-group. With a fast migrating phenyl group, a 1,2-shift affords the alkynylation product. When $\mathrm{R}$ is an alkyl group, the migration is slower and cyclopentene $\mathbf{1 3}$ is formed upon a more favorable $\mathrm{C}-\mathrm{H}$ insertion in the $\mathrm{R}$ substituent. Relying on this assumption, Ochiai and coworkers could efficiently synthesize useful terminal acetylenes derivatives by taking advantage of the fast migration of $\beta$-hydrogen ${ }^{41}$. Deprotected acetylenes were exclusively obtained also in the alkynylation of aminomalonates with TMS-substituted ethynyl iodonium salts, as reported by the group of Stang ${ }^{42,43}$. This approach could also be used for the alkynylation of further classes of enolates ${ }^{35}$, 44-46.

As a significant drawback, the mentioned methods lack generality, as their scope was restricted to few selected substrates within each class of activated carbonyl compounds. In addition, they only granted access to racemic a-alkynylated carbonyl compounds. Therefore, the use of iodonium salts for the alkynylation of enolates failed to be broadly adopted by the organic chemistry community. One of the rare recent reports by Beuerle and coworkers describes the use of TMS-protected ethynyl iodonium salt $\mathbf{1 7}$ to install a terminal acetylene onto dione 16 (Scheme 4$)^{47}$. The resulting product 18 was then used in the synthesis of apically functionalized tribenzotriquinacenes (TBTQ) 19, multi-functional molecules of interest in the field of supramolecular chemistry. The alkynylation reaction was performed in the presence of tetrabutyl ammonium fluoride (TBAF), following a protocol that had been meanwhile established with TMS-EBX (3a) (vide infra).

In 2010, the use of TMS-EBX (3a) in the presence of a fluoride source allowed Waser and coworkers to effectively accomplish the ethynylation of a broad variety of $\alpha$-cyano, $\alpha$-oxo, and $\alpha$-nitro $\beta$-ketoesters under very mild conditions ${ }^{48}$. Importantly, using chiral phase-transfer catalysis led to asymmetric induction for the 
first time in this kind of transformations. Maruoka's catalyst $\mathbf{2 1}$ gave the best results in the $\alpha$-alkynylation of $\beta$ ketoesters $^{49}$. Fine tuning of the ester substituent significantly affected the stereochemical outcome of the transformation, the highest enantiomeric excess was obtained in the alkynylation of bulky dimethylphenyl ester 20 to provide 22 (equation<smiles>COC(=O)C1Cc2ccccc2C1=O</smiles>

(20)

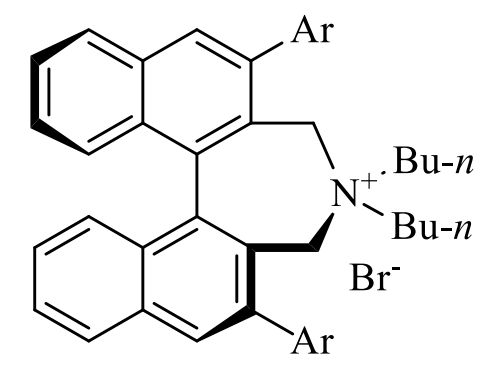

$$
\mathrm{Ar}=3,4,5-\mathrm{F}_{3} \mathrm{C}_{6} \mathrm{H}_{2}
$$

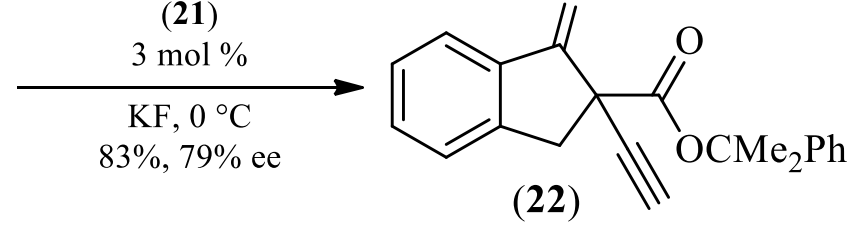

(22)

1). Higher

enantioselectivity was obtained by Maruoka and coworkers in 2014, who demonstrated that bis(trifluoromethyl)-substituted benziodoxole 8a instead of TMS-EBX was key to increase the ee to 90\%, as shown by the conversion of tert-butyl ester $\mathbf{2 3}$ into product $\mathbf{2 4}$ (equation 2$)^{50}$. In the same year, the laboratory of Waser also reported a two-step strategy involving alkynylation and Tsuji-Trost allylation for the highly enantioselective synthesis of $\alpha$-alkynyl indanones and tetralones (equation 3$)^{51}$. Allyl $\beta$-ketoester substrates were at first submitted to high yielding ethynylation using silyl-EBX $(\mathbf{3 b}, \mathbf{c})$ in the presence of diazobicyclo[5.4.0]undec-7-ene (DBU) or tetramethylguanidine (TMG) as stoichiometric bases. In the next step, palladium-catalyzed decarboxylative asymmetric allylic alkylation was performed using a ligand $\mathbf{2 5}$ developed by Trost to provide access to a-alkynyl $\alpha$-allyl ketones with up to $97 \%$ ee.<smiles>Br[Mg]c1cc2ccccc2c2c1C[N+](Br)(Br)Cc1c(Br)cc3ccccc3c1-2</smiles><smiles>COC(=O)C1Cc2ccccc2C1=O</smiles>

(20)

$$
\mathrm{Ar}=3,4,5-\mathrm{F}_{3} \mathrm{C}_{6} \mathrm{H}_{2}
$$

$$
\text { (21) }
$$

(3a)

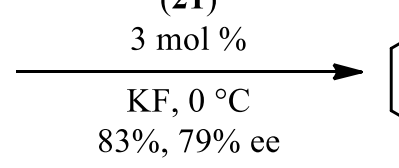<smiles>C#CC1(C(=O)OC)Cc2ccccc2C1=O</smiles>

(22) 


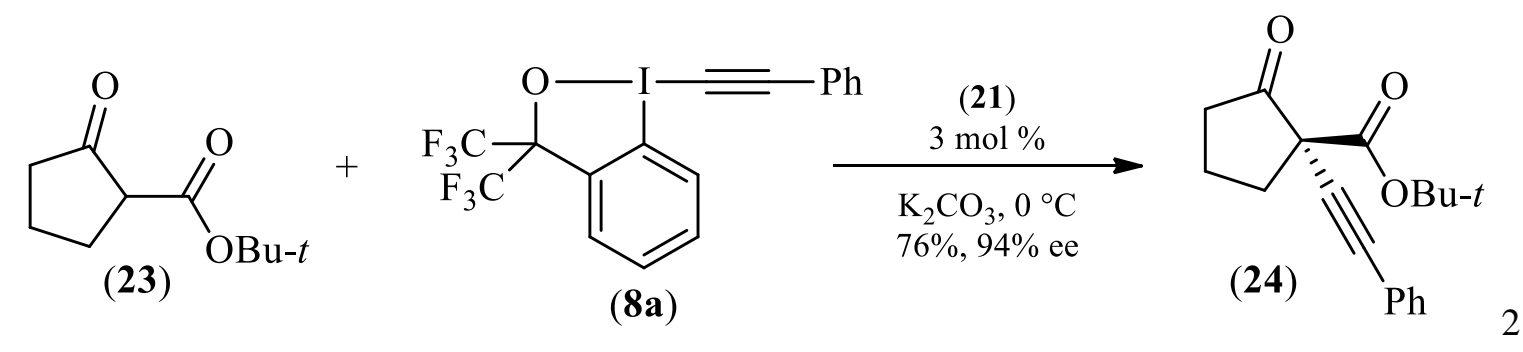<smiles>[R]C#C[C@]1(CC([R])=C)Cc2cc([R])ccc2C1=O</smiles><smiles>O=C(NC1CCCCC1)c1c(P)ccc2ccccc12</smiles>

(25)

Several applications in the total synthesis of complex natural compounds have demonstrated the versatility and robustness of the $\mathbf{\alpha}$-alkynylation of ketoesters with TMS-EBX (3a). Yang and coworkers used this method to access acetylene intermediates in the synthesis of marasmene ${ }^{52},(-)$-lingzhiol ${ }^{53}$, fragments of azadirachtin ${ }^{54}$ and retigeranic $\operatorname{acid}^{55}$, and perforanoid $\mathrm{A}^{56}$. The latter report is interesting because, for the first time, the alkynylation was not performed starting from an isolated $\beta$-ketoester but rather on the enolate generated in situ through methoxycarbonylation of lactone $\mathbf{2 6}$, to furnish directly alkynylated product 27 (equation 4 ). In a further remarkable example, Herzon and coworkers successfully employed TMS-EBX (3a) for the alkynylation of silyl enol ether $\mathbf{2 8}$ (equation 5) ${ }^{57}$. The high-yielding reaction furnished acetylene $\mathbf{2 9}$ as a single diastereoisomer, which was then utilized in the synthesis of the anti-HIV alkaloid (+)-batzelladine B. 

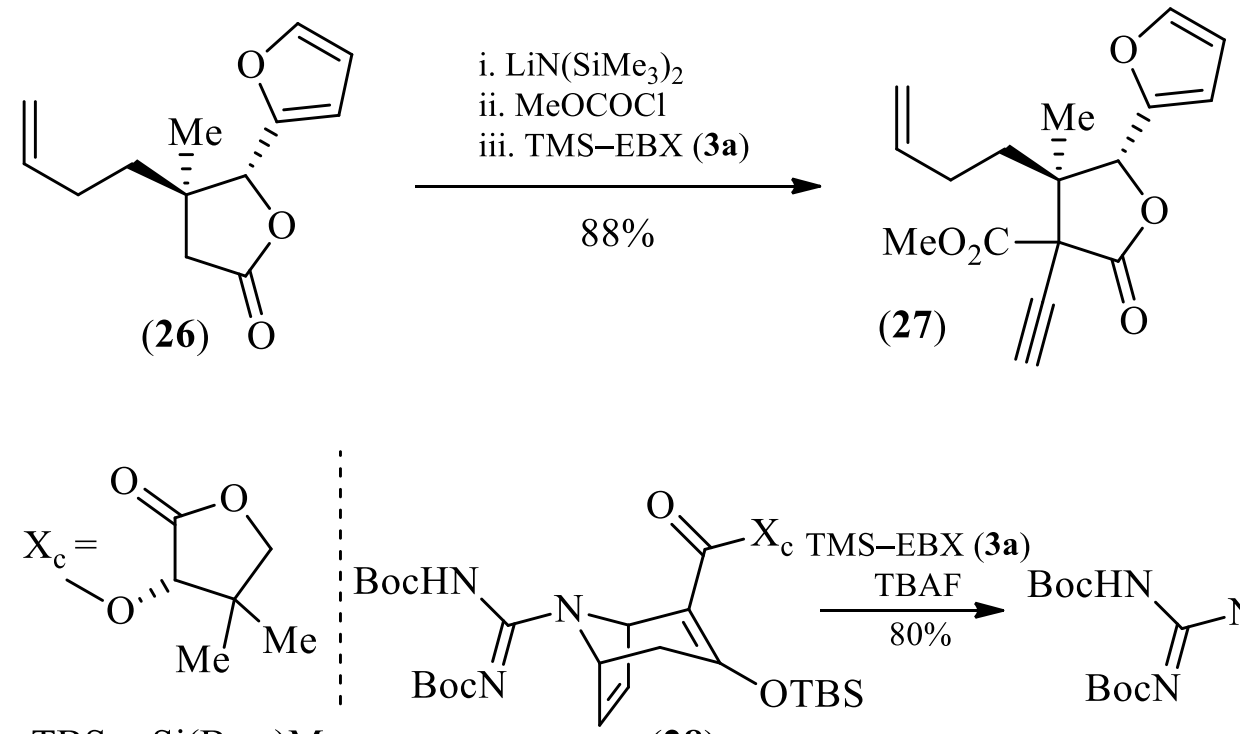

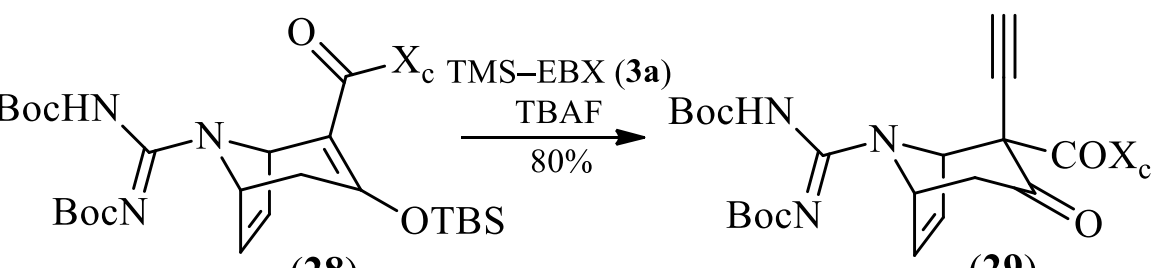

$\mathrm{TBS}=\mathrm{Si}(\mathrm{Bu}-t) \mathrm{Me}_{2}$

(28)

The effective alkynylation of other substrates than $\beta$-ketoesters with TMS-EBX 3a had been already demonstrated by Waser and coworkers in their first report ${ }^{48}$. Recently, the group of Vesely could extend the reaction scope to acidic heterocycles including pyrazolones, rhodanines, azlactones, and nitrosulfones ${ }^{58}$. With the latter substrates, moderate asymmetric induction was also possible in the presence of a cinchona-based phase transfer catalyst. The alkynylation of azlactones has been reported by Nachtsheim and coworkers, but using the alkynyl iodonium salt $\mathbf{3 0}$ combined with Hünig's base (equation 6) ${ }^{59}$. Interestingly, these conditions allowed the retention of the TMS group in the final acetylene product and could be used with azlactones bearing a linear alkyl substituent in the $\alpha$-position. With such substrates, the $\mathrm{C}-\mathrm{H}$ insertion product was normally obtained when employing TMS-EBX, suggesting that different intermediates are formed depending on the used alkynylating reagent. Compounds $\mathbf{3 1}$ are valuable starting materials to access $\boldsymbol{\alpha}$-alkynyl amino acids.<smiles>[R]C1N=C(c2ccccc2)OC1=O</smiles>
(31a) $\mathrm{R}=i$-Pr, $90 \%$
(31b) $\mathrm{R}=n-\mathrm{Bu}, 97 \%$
(31c) $\mathrm{R}=i$ - $\mathrm{Bu}, 96 \%$
(31d) $\mathrm{R}=t-\mathrm{Bu}, 60 \% 6$ 
The more challenging $\alpha$-alkynylation of non-activated carbonyl compounds remained elusive until very recently. In 2014, TMS-EBX (3aI was used by the group of Silva for the alkynylation of aromatic ketones ${ }^{60}$. The strong base $\mathrm{KO}(\mathrm{Bu}-t)$ required for the reaction to work was well tolerated by the reagent. Dialkynylation was observed with substrates having secondary a-positions. In the same publication, one example of alkynylation of aldehydes was also reported. Huang and coworkers attempted the alkynylation of aldehydes using triisopropylsilyl-EBX (TIPS-EBX, 3b) under enamine catalysis in presence of a gold co-catalyst, but $\mathbf{\alpha}$ vinylidene derivatives were obtained as the major products, whereas the desired acetylene compounds were formed only in very low yields (Scheme 5) ${ }^{61}$. Interestingly, running the reaction with an excess of $\mathbf{3 b}$ resulted in the further ethynylation of the allene products to give enynes. When the transformation was performed under oxygen, the oxidative cleavage of the enamine intermediate leading to the formation of ynones was observed ${ }^{62}$.

\section{Transition metal-catalyzed alkynylation reactions}

While the $\alpha$-alkynylation of carbonyl compounds was initially established by using iodonium salts, these reagents were not suitable for the functionalization of other types of $\mathrm{C}-\mathrm{H}$ bonds requiring transition metal catalysis. This limitation could be surmounted thanks to the superior stability of cyclic benziodoxole(on)es. In 2009, Waser and coworkers described the first direct alkynylation of indoles using TIPS-EBX (3b) with AuCl as the catalyst under mild conditions (Scheme 6) ${ }^{63}$. The $\mathrm{C}(3)$ functionalized products were obtained selectively, but the formation of $\mathrm{C}(2)$ alkynylated indoles was observed for (C3)-substituted substrates. This led to the successful alkynylation of tryptophan in peptides by Hansen and coworkers ${ }^{64}$ and Waser and coworkers ${ }^{65}$. Remarkably, Hansen and coworkers were able to use their protocol for the alkynylation of a protein in a partially aqueous solvent. This result illustrates the great potential of EBX reagents not only in organic chemistry but also in biological chemistry. In 2017, chemists at Merck used this method for the late-stage lipidation of tryptophan-containing peptides in order to improve their pharmacokinetic properties ${ }^{66}$.

The tolerance exhibited by TIPS-EBX (3b) toward many reaction conditions allowed to optimize the alkynylation process with other heterocycles, including pyrroles ${ }^{39}$ as well as less reactive (benzo)thiophenes ${ }^{67}$ and (benzo)furans (Scheme 6) ${ }^{68,69}$. Nierth and Marletta reported in 2014 that biologically relevant protoporphyrin IX could be effectively alkynylated under gold catalysis with TIPS-EBX (3b) and a Cu II $^{\text {co- }}$ catalyst ${ }^{70}$. Even though the reaction furnished a mixture of regioisomers, the alkynylation of porphyrins remains of great interest for biolabeling studies. More recently, 2-pyridones and isoquinolones have also been alkynylated successfully with TIPS-EBX (3b) under gold catalysis by the groups of $\mathrm{Li}^{71}$ and Patil ${ }^{72}$ respectively. In both these works, best results were obtained at moderately high temperatures; moreover, the addition of an excess of a strong Brønsted acid was necessary for the reaction with 2-pyridones. 
TIPS-EBX (3b) was also found effective in the alkynylation of electron-rich arenes (Scheme 6): the functionalization of $N$-(di)benzyl anilines and polymethoxy benzenes was reported by Brand and Waser in $2012^{73}$. In 2017, Tolnai and Novák and coworkers successfully extended the gold catalyzed direct alkynylation with TIPS-EBX (3b) to azulenes ${ }^{74}$. The latter reaction worked under very mild conditions (room temperature, no additive) and tolerated many functional groups including halogens and carbonyl substituents. Interestingly, only the five-membered ring was alkynylated.

Elucidating the mechanism of these direct $\mathrm{C}-\mathrm{H}$ alkynylation reactions was particularly challenging as the isolation of well-defined gold complexes was difficult in the absence of phosphine ligands. Two hypotheses were initially proposed by Waser and coworkers, evoking either a $\pi$-activation or an oxidative catalytic cycle ${ }^{39}$, ${ }^{63}$. A detailed mechanistic investigation undertaken by Ariafard using computational methods rules out both pathways because they would require too high energy for reactions occurring at room temperature ${ }^{75}$. A lower energy alternative pathway was identified (Scheme 7), involving $\pi$-activation of the $\mathrm{C} \equiv \mathrm{C}$ triple bond in TIPSEBX (3b) to generate intermediate $\mathbf{3 3}$ followed by transfer of the ethynyl group from the $\mathrm{I}^{\mathrm{III}}$ to $\mathrm{Au}^{\mathrm{I}}$ center. At this point, the nucleophilic attack of the indole substrate $\mathbf{3 5}$ on $\mathbf{3 4}$ would be followed by $\beta$-elimination from the resulting intermediate $\mathbf{3 6}$ and rearomatization to provide the alkynylation product $\mathbf{3 7}$.

Using TIPS-EBX (3b) under gold catalysis usually results in a highly regioselective alkynylation process, the most electron-rich C-H position in the (hetero)arene being favored. In 2013, Waser and coworkers demonstrated that the selective $\mathrm{C}(2)$-alkynylation of indoles could be obtained under palladium catalysis ${ }^{76}$. As a further important advancement in this research area, it was demonstrated that EBX reagents could be conveniently used for the direct alkynylation of $\mathrm{C}\left(\mathrm{sp}^{2}\right)-\mathrm{H}$ bonds through a directing-group approach. In 2014, Feng and Loh described the high yielding ethynylation of benzene rings and heterocycles bearing a pivaloyl amide directing group with TIPS-EBX (3b) under $\mathrm{Rh}^{\mathrm{III}}$ catalysis at room temperature (equation 7$)^{77}$. Shortly thereafter, Glorius and coworkers reported similar results with benzamides and enamides (equation 8 ) $^{78}$. A further important contribution was then made by the research group of $\mathrm{Li}$, who published an exhaustive investigation on the alkynylation of (hetero)aromatic substrates with silyl and alkyl EBX reagents (equation $9)^{79}$. While the efficiency of pivaloyl amide as a directing group was again shown in this report, other functionalities and heterocycles including pyridine, pyrazoles, pyrimidines, and oximes could also be used. In the same work, the first examples of $\mathrm{Ir}^{\mathrm{III}}$-catalyzed alkynylation reactions were also provided, the best results being afforded in this case by an $N$-methoxy amide directing group. 


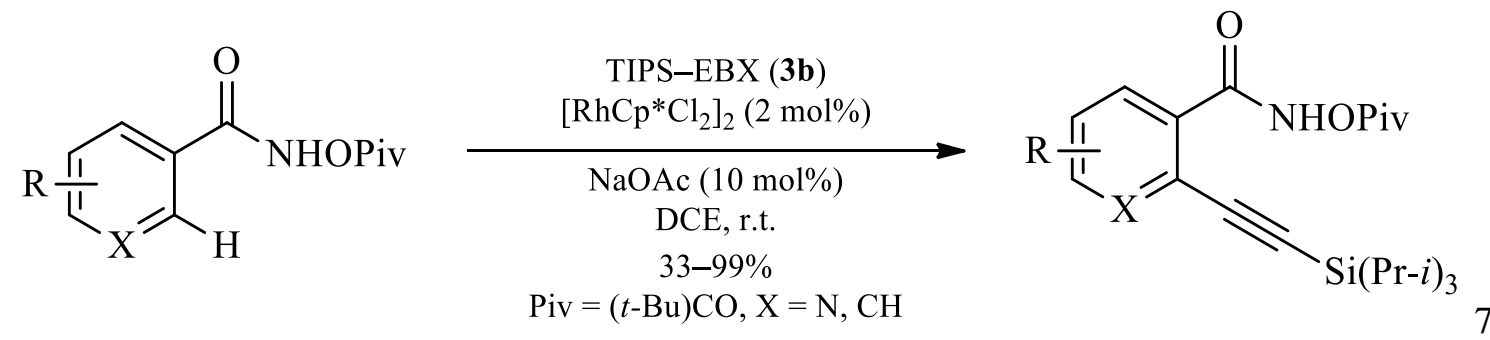

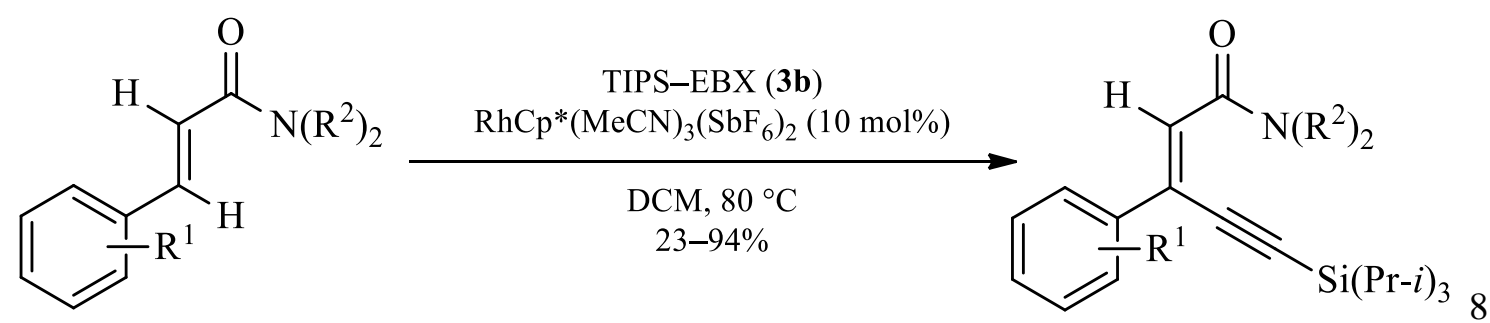<smiles>[R]C#CC1=C([R9])C=C[R1]C=C1</smiles>

Based on preliminary studies conducted by Feng and Loh and - independently - Li and coworkers, two mechanistic scenarios were hypothesized for the $\mathrm{Rh}^{\mathrm{III}}$ - or $\mathrm{Ir}^{\mathrm{III}}$-catalyzed direct alkynylation (Scheme 8 ). In the case of rhodium catalysis, the initial activation of the catalyst with metal salts and the subsequent reaction with the substrate would lead to the formation of rhodacycle $\mathbf{3 8}$, probably through a metalation-deprotonation pathway. At this point, as a first possibility, the EBX reagent could react with complex $\mathbf{3 8}$ via a highly regioselective insertion to form intermediate 39. This step would be followed by the $\alpha$-elimination of an iodonium leaving group. From reactive $\mathrm{Rh}^{\mathrm{III}}$-allenylidene 40, a 1,2-shift of aryl would then permit the release of the alkynylated product and complex 41. In the alternative pathway, upon coordination of the EBX reagent to 38 to form 42, oxidative addition to $\mathrm{Rh}^{\mathrm{III}}$ would afford $\mathrm{Rh}^{\mathrm{V}}$-species 43 . Reductive elimination from the latter would then result in the product and complex 41, which can reenter the catalytic cycle via metalationdeprotonation.

After these pioneering works, a growing number of reports have appeared in this area. Both substrates and directing groups have been extensively surveyed. The direct alkynylation olefins was realized by Loh and coworkers under $\mathrm{Rh}^{\mathrm{III}}$-catalysis using both acrylamides ${ }^{80}$ and enamides ${ }^{81}$. Indolines could be ethynylated selectively at the C(7)-position as reported independently by the groups of $\operatorname{Loh}^{82}$, $\mathrm{Zhu}^{83}$, and - using an Ir ${ }^{\mathrm{III}}$ 
catalyst - $\mathrm{Li}$ and $\mathrm{Zhou}^{84}$. The selective ortho-ethynylation of $\mathrm{N}$-pyridyl and $\mathrm{N}$-pyrimidyl anilines was also achieved under Ir ${ }^{\mathrm{III}}$-catalysis by Tang and coworkers ${ }^{85}$. N-Oxides could be used as competent directing groups as proved by the $\mathrm{C}(8)$-alkynylation of quinoline- $N$-oxides accomplished by Chang and coworkers under the catalysis of cationic $\mathrm{Rh}^{\mathrm{III}}$ species ${ }^{86}$. Azomethine ylides were also employed to direct the alkynylation of (hetero)aromatic substrates by the group of $\mathrm{Li}^{87}$. Finally, a method for the $\mathrm{C}-\mathrm{H}$ ethynylation of benzene rings was developed by Li and coworkers under iridium catalysis using 7-azaindoles heterocycles as directing groups $^{88}$.

Whereas the alkynylation of heterocycles achieved with TIPS-EBX (3b) under Au ${ }^{\mathrm{I}}$ catalysis exhibited high regioselectivity for the most electron rich $\mathrm{C}-\mathrm{H}$ bond, the use of directing groups in rhodium- or iridiumcatalyzed $\mathrm{C}-\mathrm{H}$ activation processes permitted to introduce the acetylene group onto other, less reactive positions. For example, the C(3)-alkynylation of 2-pyridones was obtained by the group of $\mathrm{Li}$ with a $\mathrm{Rh}^{\mathrm{III}}{ }_{-}$ catalyst and an easily removable $N$-pyrimidyl directing group (equation 10$)^{71}$. As previously mentioned, these substrates are exclusively functionalized on the $\mathrm{C}(4)$-position when using gold catalysis (vide supra). In the case of isoquinolones, Patil and coworkers showed that the amide carbonyl of the substrate was effective to direct the alkynylation selectively on the $\mathrm{C}(8)$-position (equation 11$)^{72}$. Kang and Hong reported similar selectivity with quinolones ${ }^{89}$. On the other side, they showed that with a pyrimidyl directing group installed on the amide nitrogen the alkynylation in the $\alpha$-position was possible using either a $\mathrm{Rh}^{\mathrm{III}}$ - or a $\mathrm{Ru}^{\mathrm{II}}$-catalyst.
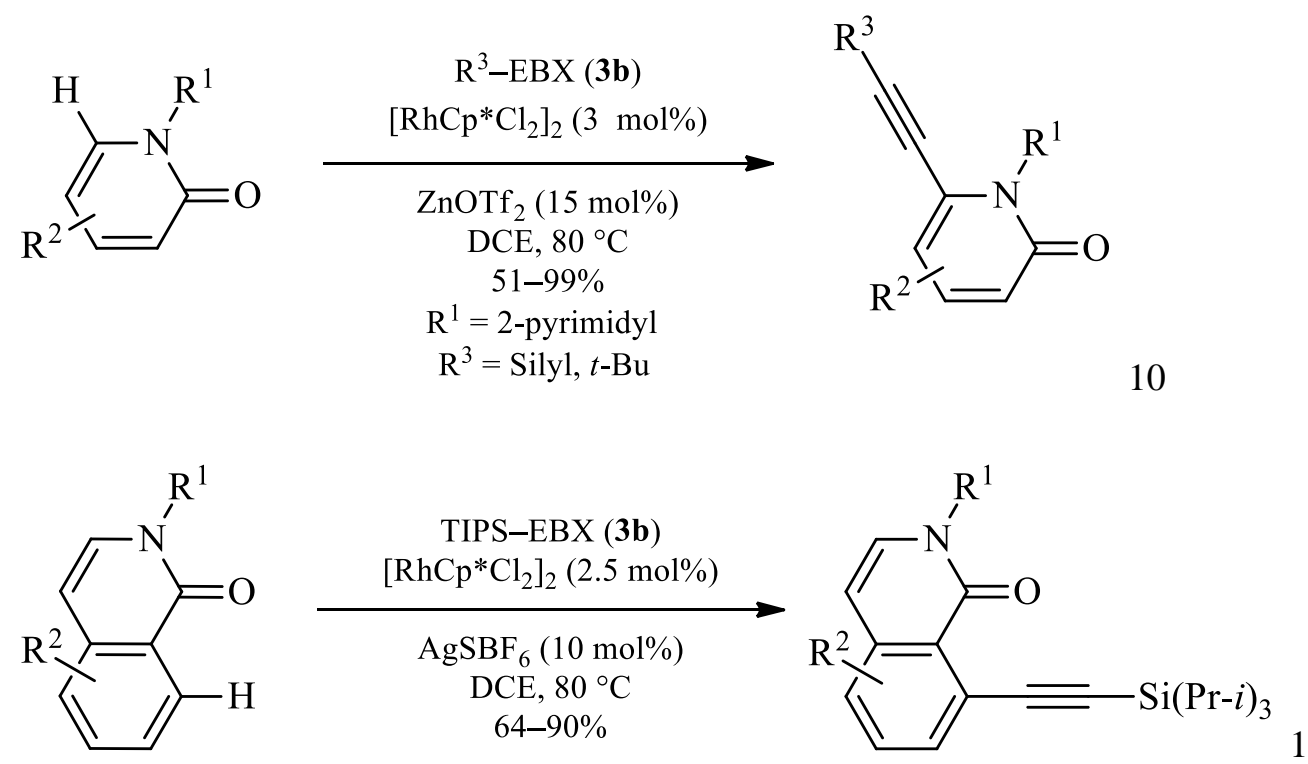

In this last report, the use of a moderately priced ruthenium complex is valuable if compared to the much more expensive rhodium and iridium species employed in the aforementioned methods. In this perspective, one important contribution was made by Cheng and coworkers, who succeeded in developing a general method for 
the alkynylation of a large variety of substituted benzenes and heterocycles using $\left[\operatorname{RuCl}_{2}(p \text {-cymene) }]_{2}\right.$ as the catalyst (equation 12$)^{90}$. The reaction worked in moderate to very good yield and could be performed under mild conditions using an $\mathrm{N}$-methoxy amide as the directing group. Cobalt catalysis was found efficient for the $\mathrm{C}-\mathrm{H}$ alkynylation of indoles by Shi and coworkers (equation 13) ${ }^{91}$. High C(2)-selectivity was obtained with an $N$ pyrimidyl directing group, which could be removed afterwards. As a drawback, the reaction required high temperatures to work in good yields.<smiles>[R]C#Cc1cc([R])ccc1C(=O)NOC</smiles><smiles>[R]C#Cc1cc2cccc([R])c2n1[R6]</smiles>

Further efforts to expand the scope of the directed $\mathrm{C}\left(\mathrm{sp}^{2}\right)-\mathrm{H}$ functionalization with EBX reagents have targeted other substrates than (hetero)arenes and olefins. In particular, the alkynylation of aldehydes under rhodium or iridium catalysis led to an alternative access to ynones. Such a method was first developed by Li and coworkers, who reported the alkynylation of benzaldehydes bearing ortho-hydroxy or sulfonamides directing groups ${ }^{92}$. A similar reaction was then reported by Yang and coworkers with 8-quinolinecarbaldehyde substrates ${ }^{93}$.

Another important advancement in this field was achieved by Nachtsheim and coworkers in 2015, showing that an uncommon free $\mathrm{OH}$ directing group could be used in the alkynylation of the alkene $\mathrm{C}-\mathrm{H}$ bond in vinyl phenols (equation 14$)^{94}$. The reaction, which worked under $\mathrm{Rh}^{\mathrm{III}}$-catalysis at room temperature, delivered Zenyne products with high selectivity. The authors found that the more reactive TIPS-EBX* 44, previously described by Waser and coworkers ${ }^{39}$, was important in order to shorten the reaction time and obtain better yields. It was assumed that the ortho-methyl substituent in this reagent prevented the counterproductive insertion of $\mathrm{Rh}^{\mathrm{III}}$ into 2-iodobenzoic acid, a normal by-product when using simple TIPS-EBX (3b). More recently, the same research group has extended this transformation to $\mathrm{N}$-unprotected vinylanilines (equation $15)^{95}$. In this case, success relied on the use of iridium catalysis, as the reaction did not work with rhodium catalysts, which are more susceptible to deactivation in the presence of free amines. Moreover, TIPS-EBX (3b) 
could be used, as Ir ${ }^{\mathrm{III}}$ does not easily undergo insertion into 2-iodobenzoic acid. The addition of a catalytic amount of pyridine was needed to shorten the otherwise long reaction time. With both vinyl phenols and anilines, high yields were obtained especially with terminally unsubstituted substrates. No conversion was observed when the hydroxy- or the amino-group was in meta or para positions, proving the need for having the directing group ortho to the alkene. Concerning the mechanism, the authors suggested that the reaction occurs through insertion-elimination-shift catalytic cycle involving a less common six-membered rhoda- or iridacycle. However, an oxidative addition pathway could not be completely ruled out.
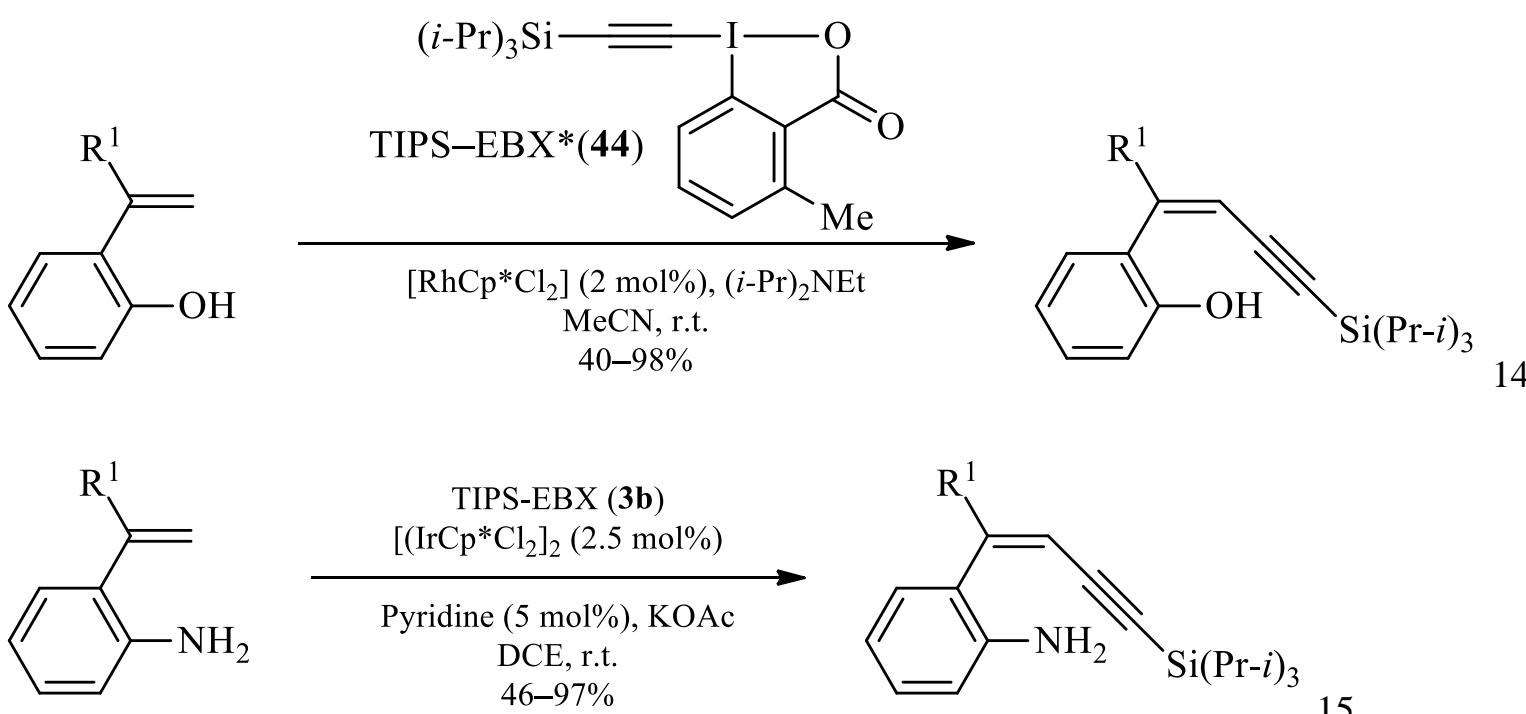

\section{Alkynylation of carbon radicals}

When considering the direct functionalization of $\mathrm{C}-\mathrm{H}$ bonds, the alkynylation of $\mathrm{C}$-radicals generated though homolytic $\mathrm{C}-\mathrm{H}$ cleavage stands as a valuable alternative to the methods depending on transition metal catalysis, which frequently require directing groups. The use of alkynyl hypervalent iodine reagents in this area has been a focus of the chemical research only in recent years and has exclusively concerned cyclic ethynyl benziodoxolones in both stoichiometric and catalytic oxidative processes. These reagents have shown a great aptitude to react with C-radicals to form, through different mechanisms, the corresponding acetylene derivatives and a benziodoxole radical, which enables the propagation of the process.

The alkynylation of aliphatic C-radicals was first described by the group of Yu and $\mathrm{Chen}^{96}$ and has been more recently revisited by Feng and coworkers ${ }^{97}$. tert-Butyl hydroperoxide (TBHP) or di-tert-butylperoxide (DTBP) were employed as suitable oxidants to promote hydrogen abstraction whereas the so-generated C-radical could be intercepted with aryl- and silyl-EBX reagents (products 45-46) (Scheme 9). Similar conditions were applied also to the synthesis of ynones (products 47-48) through the $\mathrm{C}\left(\mathrm{sp}^{2}\right)-\mathrm{H}$ oxidative alkynylation of aldehydes. This 
transformation was reported nearly simultaneously by the groups of Zhu and $\mathrm{Wei}^{98}$, Chen and $\mathrm{Yu}^{99}$, and Song and $\mathrm{Li}^{100}$ in 2015. Also in these works, TBHP or DTBP were used to generate acyl radicals. Moderate to good yields were obtained starting from a vast diversity of (hetero)aromatic as well as aliphatic aldehydes. For the successful outcome of these reactions, temperatures up to $130{ }^{\circ} \mathrm{C}$ were usually required.

The direct C-H alkynylation methods suffer from significant drawbacks. Firstly, poor selectivity and reactivity are an issue in the absence or polarizing heteroatoms. Secondly, high temperatures are necessary for the effective radical generation and thirdly a large excess of substrates is required in the case of $\mathrm{C}\left(\mathrm{sp}^{3}\right)-\mathrm{H}$ alkynylation. Higher selectivity and milder conditions for the ethynylation of C-radicals were reported by Cheng and coworkers using a decarboxylative reaction ${ }^{101}$. This approach is based on the one-electron oxidation of primary, secondary, and tertiary carboxylic acids in the presence of a silver catalyst and a stoichiometric amount of potassium persulfate as the final oxidant. Under these conditions, the initially generated carboxyl radicals underwent the loss of $\mathrm{CO}_{2}$ to release alkyl radicals. The latter were then trapped with TIPS-EBX (3b) to deliver the alkynylation products in high yields. As a synthetically useful expansion of the scope of this transformation, Chen and Hashmi recently described the direct decarboxylative alkynylation of aromatic difluoroacetic acids using aryl, alkyl, and silyl EBX reagents (equation 16) ${ }^{102}$. This method also involved a silver catalyst together with potassium persulfate as the stoichiometric oxidant. Interestingly, $\mathrm{Wu}$ and $\mathrm{Wu}$ shortly later developed a metal-free variant of this method, therefore demonstrating that the silver catalyst is not necessary for the successful outcome of the process ${ }^{103}$. Finally, the use of $\alpha$-ketoacids as suitable substrates for the reaction was reported independently by the groups of Duan ${ }^{104}$ and Feng and $\mathrm{Xu}^{105}$, providing further access to aromatic and aliphatic ynones. Also in this case, the reaction did not require a transition metal catalyst, and could be effectively performed with a slightly substoichiometric amount of persulfate. Noteworthy, the procedure could be extended to oxamic acids, granting access to useful propiolamides (equation 17) ${ }^{104}$.<smiles></smiles><smiles>[R]C#CC(F)(F)c1ccncc1</smiles> 
<smiles>[R]C(=O)C(=O)O</smiles><smiles>[R]N([R])C(=O)C(=O)O</smiles>

$+\mathrm{R}^{3}-\mathrm{EBX}(3) \underset{\mathrm{MeCN} / \mathrm{H}_{2} \mathrm{O}(1: 1), 50^{\circ} \mathrm{C}}{\stackrel{\mathrm{K}_{2} \mathrm{~S}_{2} \mathrm{O}_{8}(0.7 \text { equiv) }}{\longrightarrow}}$ $25-92 \%$<smiles>[R]C#CC([R])=O</smiles><smiles>[R]C#CC(=O)N([R])[R]</smiles>

In spite of the good chemo- and regio-selectivity observed with readily available and inexpensive carboxylic acids, the aforementioned methods still suffer from the necessity of a stoichiometric strong oxidant. Photoredox catalysis offered an effective expedient to overcome this disadvantage, giving access to C-radicals under milder oxidative conditions ${ }^{106}$. As a first notable example, Chen and coworkers reported in 2014 the deboronative alkynylation of trifluoroborate salts using EBX reagents and a ruthenium catalyst 49 (Figure 1) under visible light irradiation (equation 18) ${ }^{107}$. The transformation exhibited great versatility as it could be applied to the transfer of alkyl, aryl, and silyl ethynyl groups to primary, secondary, and tertiary substrates in good to excellent yields. Importantly, hydroxy benziodoxolone (2) was required as an additive for the reaction to work. It probably acted as the initiator of the catalytic cycle by permitting the oxidation of the photoactivated ruthenium(II) catalyst. A similar strategy was then applied by the same authors to the decarboxylative alkynylation of $\alpha$-ketoacids with ruthenium photocatalyst 49, again resulting in an efficient synthesis of ynones (equation 19$)^{108}$.

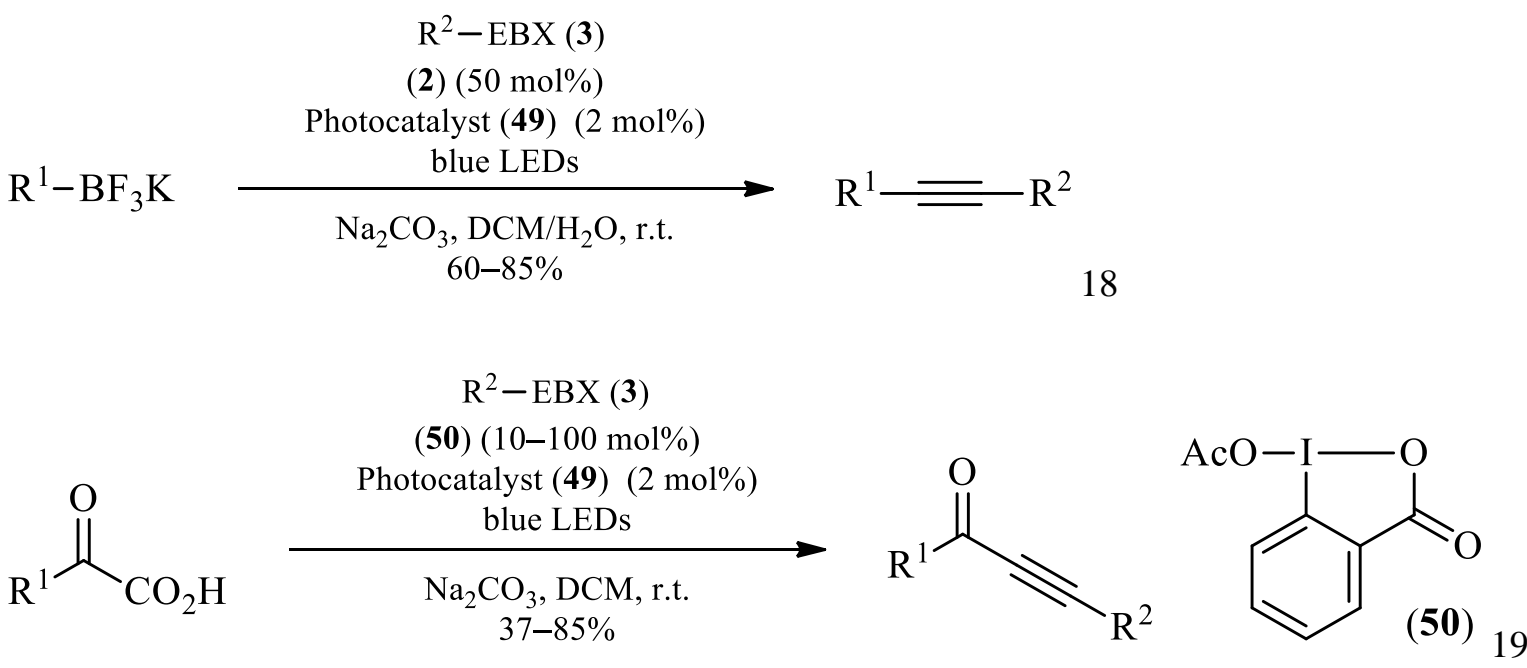

In 2015, the great potential of photoredox catalysis to promote efficient decarboxylative alkynylation was further highlighted by the works of $\mathrm{Lu}$ and $\mathrm{Xiao}^{109}$ and, independently, Waser and coworkers (Scheme 10) ${ }^{110}$. 
Both laboratories described the efficient synthesis of acetylenes from a large variety of easily accessible carboxylic acids by using EBX reagents under basic conditions in the presence of an iridium photoredox catalyst 51 (Figure 1). The reaction worked effectively under irradiation with commercially available blue LEDs or sun light. Excellent results were especially obtained starting for both $\alpha$-amino and $\alpha$-oxo acids, but the transformation also performed well in the absence of heteroatoms in the $\alpha$-position to the carboxy group. Concerning the scope of EBX reagents, the group of Lu and Xiao focused predominantly on the use of aryl EBX (examples: products 54-56), whereas the procedure established by Waser and coworkers was especially effective for the transfer of versatile silyl alkynyl groups (example: product 53). The process could provide access to ynones when performed under an atmosphere of $\mathrm{CO}^{109}$. Finally, the same reaction has been more recently re-explored by $\mathrm{Li}$ and coworkers to examine the use of organic dyes as less expensive alternatives to iridium-based photocatalysts 51 (Scheme 10) ${ }^{111}$. 9,10-Dicyanoanthracene (DCA) (52) (Figure 1) proved to be a valuable replacement for $\mathbf{5 1}$ and led to successful decarboxylative alkynylation with both aryl and silyl EBX reagents (products 53-56).

The mechanism of the photoredox iridium-catalyzed decarboxylative alkynylation was studied in detail by Waser and coworkers both experimentally and with the aid of computational methods ${ }^{112}$. They proposed that the catalytic cycle is initiated by the single-electron oxidation of the deprotonated carboxylic acid by the strongly oxidizing photo-activated form of the $\mathrm{Ir}^{\mathrm{III}}$-catalyst (Scheme 11). Extrusion of $\mathrm{CO}_{2}$ would then deliver a Cradical, whose existence was proved by experiments with cyclopropyl radical clock reagents. At this point, DFT calculations showed that two pathways with similar energies may be followed. The newly generated radical can undergo a concerted $\alpha$-addition onto the EBX reagent through transition state $\mathbf{5 7}$ to form directly the product and benziodoxonyl radical 58. This mechanism is different from the one originally proposed by Cheng and coworkers in their seminal work ${ }^{101}$, who had rather proposed a non-concerted $\alpha$-addition-elimination pathway involving intermediate radical 60. Alternatively, $\beta$-addition would result in intermediate 61. Radical elimination from the latter then yields 59 and the alkynylation product through 1,2-shift from $\mathbf{6 1}$ via carbene $\mathbf{6 2}$. Reduction of $\mathrm{Ir}^{\mathrm{II}}$ by the benziodoxonyl radical $\mathbf{5 9}$ would than complete the photocatalytic cycle. The calculated energies for the transitions states of these two mechanistic routes were very close $\left(17.2 \mathrm{kcal} \mathrm{mol}^{-1}\right.$ for the concerted $\alpha$ addition versus $16.8 \mathrm{kcal} \mathrm{mol}^{-1}$ for the $\beta$-addition). A third possible mechanism relying on a single electron transfer between the alkyl radical and the EBX reagent was excluded after computations showed it would be too high in energy.

As a further valuable application in this domain, EBX reagents have been recently used for alkynylation of the $\mathrm{C}$-radicals generated through the $\mathrm{C}-\mathrm{C}$ bond cleavage of tertiary alkanol substrates under one-electron oxidation conditions. This tandem process is particularly interesting as it permits to synthesize ketone products bearing a distal acetylene group. A first example of this type of transformation was reported by Duan and coworkers in 
$2015^{113}$, and consisted in the homolytic ring-opening/alkynylation of cyclic alcohols using silyl, aryl, and alkyl EBX reagents with sodium persulfate as the stoichiometric oxidant (equation 20). The reaction worked with tertiary cyclopropanols, cyclobutanols, and even cyclopentanols, affording linear $\beta-, \gamma^{-}$, and $\delta$-ethynyl ketones in good to excellent yields. The procedure could be applied to the synthesis of both aliphatic and aromatic ketones. Under very similar conditions, Chen and coworkers later observed that tertiary styryl cyclobutanols underwent a cascade alkynylation/ring expansion rearrangement to yield $\alpha$-propargyl cyclopentanones (equation $21)^{114}$. Only aryl EBX reagents were used in this transformation. In the same report, tertiary alkynyl cyclobutanols were also used, which could be converted into ene-yne cyclopentanones in moderate yields by using TIPS-EBX (3b).<smiles>[R]C#CCCCC(C)C([R])=O</smiles>

$$
\begin{gathered}
\mathrm{R}^{1}=\text { Alkyl, (hetero)aryl } \\
n=1,2,3
\end{gathered}
$$

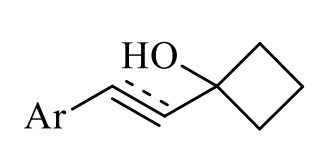

R-EBX (
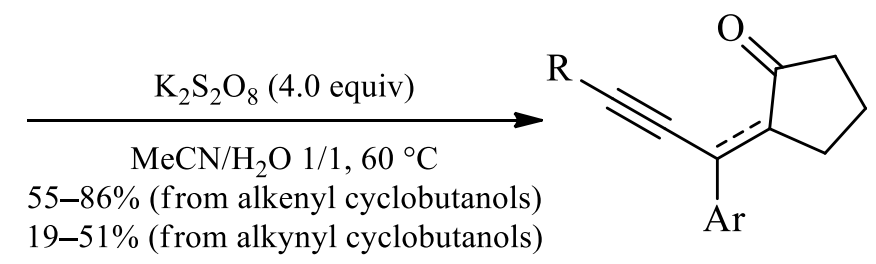

21

The method described by the group of Duan was later re-investigated by Chen and coworkers ${ }^{115}$. These authors showed that the radical fragmentation of tertiary alcohols could also be efficiently achieved under the mild photoredox catalysis conditions previously established for the decarboxylative alkynylation process.

Specifically, combining ruthenium catalyst 49 with acetoxy benziodoxolone (50) under visible light irradiation permitted the successful oxidative $\mathrm{C}\left(\mathrm{sp}^{3}\right)-\mathrm{C}\left(\mathrm{sp}^{3}\right)$ homolytic bond cleavage and ring opening of tertiary cyclopropanols and cyclobutanols. The alkynylation of the resulting primary radicals using aryl EBX reagents led to distal alkynyl ketones in high yields (equation 22). The same approach could be also applied to tertiary dibenzylic linear alcohols, which could be used as a source of alkyl radicals to generate aromatic acetylenes after reaction with aryl EBX reagents. Finally, the method could be extended to $\beta$-amide, $\beta$-ester, and $\beta$-keto alcohols, offering a route for the synthesis of ynamides, ynoates, and ynones (equation 23$)^{116}$. A tertiary benzyl alcohol group was used again to achieve carbonyl-C $\left(\mathrm{sp}^{3}\right)$ bond cleavage with high selectivity. 


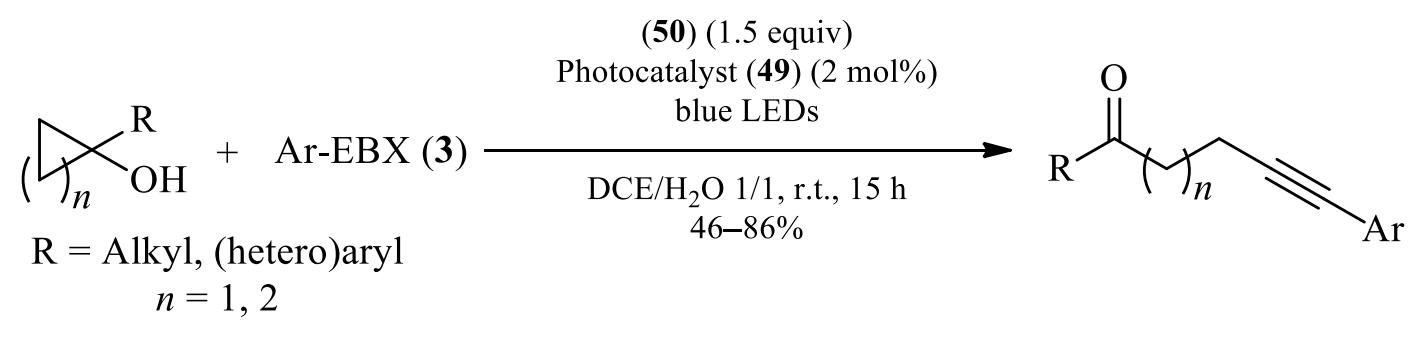

(50) $(2.0$ equiv)

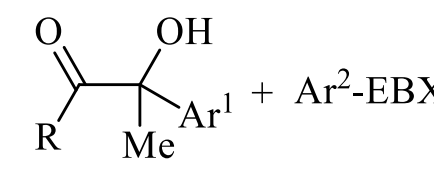

$$
\begin{gathered}
\mathrm{R}=\mathrm{R}^{1} \mathrm{R}^{2} \mathrm{~N}, \mathrm{R}^{1} \mathrm{O}, \text { Alkyl, Aryl } \\
\mathrm{Ar}^{1}=p \text {-OMe-Ph }
\end{gathered}
$$

The authors proposed that the process is initiated by the oxidation of the photoactivated form of the $\mathrm{Ru}$ (I $c a t a l y s t$ by acetoxy benziodoxolone (50) or the radical resulting from its decomposition (Scheme 12). The alcohol substrate is then activated through the reaction with $\mathbf{5 0}$ to form isolable complex $\mathbf{6 3}$. The oxidation of the latter by $\mathrm{Ru}{ }^{\mathrm{III}}$ permits to close the photoredox catalytic cycle and generates an alkoxyl radical, whose decomposition releases ketone by-product $\mathbf{6 4}$ and the alkyl radical that can finally react with the EBX reagent to give the acetylene product.

\section{Alkynylation as part of Domino reactions}

In most of the alkynylation reactions examined so far, the transfer of the acetylene group was not accompanied by any other bond-forming event. While the great synthetic utility of these transformations remains undeniable, it is clear that combining the alkynylation step with the formation of an additional $\mathrm{C}-\mathrm{C}$ or $\mathrm{C}-\mathrm{X}$ ( $\mathrm{X}=$ heteroatom) bond would allow a significant gain in efficiency. For these reasons, cascade reactions involving electrophilic alkynylating reagents are highly interesting. Probably because of their instability when exposed to transition metals, no example describing the use of alkynyl iodonium salts in domino processes has been reported. By contrast, more stable EBX reagents have been increasingly applied in this area.

In 2010, a first example was reported by Waser and coworkers consisting in the Pd ${ }^{\mathrm{II}}$-catalyzed intramolecular oxy-alkynylation of non-activated olefins with phenols and carboxylic acids ${ }^{117}$. Upon adjusting the reaction conditions, they could extend this concept to the amino-alkynylation of olefins with $N$-tosyl amides (equation $24)^{118}$. In both procedures, the use of TIPS-EBX (3b) was essential for the success of the transformation, which resulted in an efficient alkene difunctionalization through the simultaneous formation of a $\mathrm{C}-\mathrm{O} / \mathrm{C}-\mathrm{N}$ and a $\mathrm{C}\left(\mathrm{sp}^{3}\right)-\mathrm{C}(\mathrm{sp})$ bonds. The amino-alkynylation reaction was especially interesting because it gave a facile access 
to a variety of saturated heterocycles bearing a useful propargylic group. Apart from lactams, also oxazolidinones and imidazolidinones could be synthesized in good yields. The best results were achieved using a catalytic amount of palladium dichloride with an excess of lithium chloride, suggesting that the actual catalytic species should be an in situ generated palladate complex.<smiles></smiles>
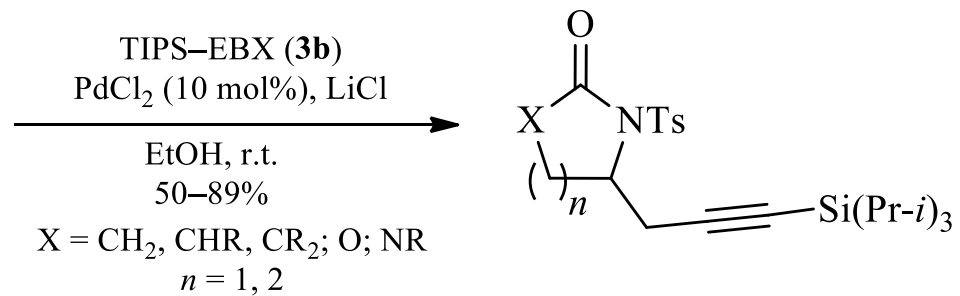

Waser and coworkers then turned their attention to domino reactions leading to the synthesis of aromatic heterocycles through the formation of a $\mathrm{C}\left(\mathrm{sp}^{3}\right)-\mathrm{C}\left(\mathrm{sp}^{2}\right)$ bond. As a first attempt in this direction, they described the one-pot synthesis of 3-alkynyl indoles upon reaction of unprotected 2-ethynylanilines with TIPS-EBX (3b) under gold catalysis ${ }^{119}$. However, this transformation cannot be defined as a true domino reaction because, while an $\mathrm{Au}^{\mathrm{III}}$-catalyst mediated the initial cyclization event, a different $\mathrm{Au}^{\mathrm{I}}$ was required for the subsequent alkynylation step. In 2013, a true domino cyclization-alkynylation process was established by the same research group, who reported the conversion of keto allenes into alkynyl furans by using silyl benziodoxole $\mathbf{8 b}$ and $\mathrm{Au}^{\text {III }}$ catalyst 65 (equation 25$)^{68}$. Aryl- and alkyl-substituted furans bearing an acetylene group on the C(3)-position could be obtained in very good yields. Noteworthy, such compounds cannot be synthesized otherwise through direct $\mathrm{C}-\mathrm{H}$ alkynylation. It is also important to remark that the fine tuning of the hypervalent iodine reagent was crucial and high yields were obtained only upon switching from TIPS-EBX (3b) to the fluorinated reagent 8b.<smiles>[R]C(=O)C([R])=C=C</smiles>

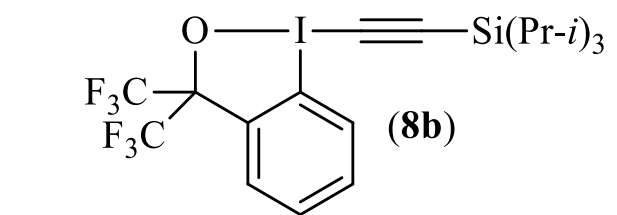
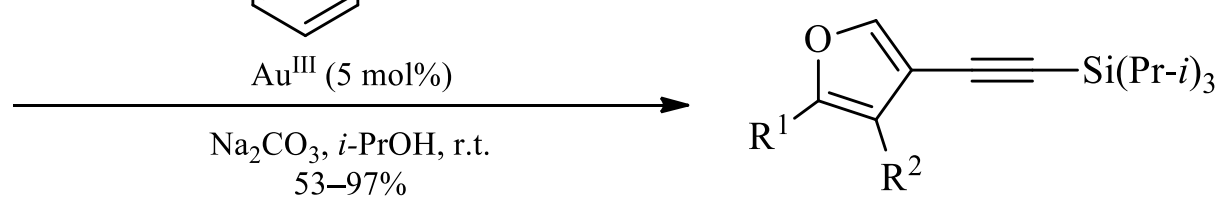

The same reagent was also key to the development of a further domino reaction, reported by Li and Waser as an efficient route to 5- or 6-alkynylated indoles (equation 26$)^{120}$. Specifically, indoles bearing an ethynyl group on 
the $\mathrm{C}(5)$ - or $\mathrm{C}(6)$-position could be selectively synthesized starting from 2- or, respectively, 3- homopropargyl pyrroles. The value of this transformation becomes especially evident when considering that the ethynylation of the benzene ring of indoles is not easily achieved without its prefunctionalization. In contrast to the previously discussed methods, the reaction did not work with either a $\mathrm{Au}^{\mathrm{I}}$ or a $\mathrm{Au}^{\mathrm{III}}$ catalyst, but was efficient using a $\mathrm{Pt}^{\mathrm{II}}$ catalyst.
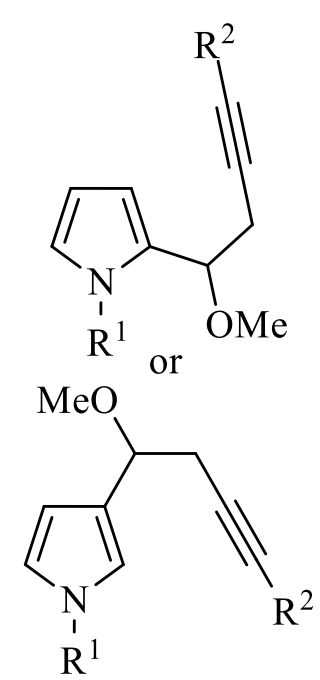

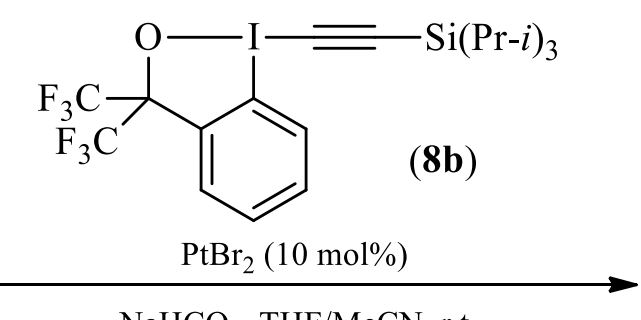

$\mathrm{NaHCO}_{3}, \mathrm{THF} / \mathrm{MeCN}$, r.t.

$34-84 \%$
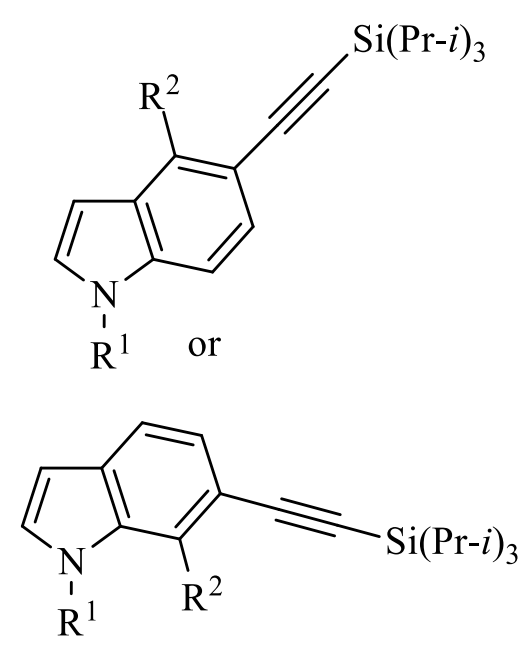

In 2016, two additional cyclization/alkynylation domino reactions were reported by Patil and coworkers, again using TIPS-EBX (3b) and an Au ${ }^{\mathrm{I}}$-catalyst. At first, they described the amino-alkynylation of acetylenes with an intramolecular pyridyl group to access quinalizinones (equation 27) ${ }^{121}$. This process was hypothesized to occur through the initial gold-mediated activation of the $\mathrm{C} \equiv \mathrm{C}$ triple bond, followed by the nucleophilic attack of the pyridine nitrogen atom, alkynylation of the resulting $\mathrm{Au}^{\mathrm{I}}$ complex, and rearomatization. The transformation was conveniently applied to the synthesis of a variety of diversely substituted polycyclic heterocycles.<smiles>[R]C#Cc1ccccc1-c1cccc(OC)n1</smiles>

via:<smiles>[R]c1cccc2c1c([Al])c([R])[n+]1c(OC)cccc21</smiles><smiles>[R][M][SiH2]C#Cc1c([R])n2c(=O)cccc2c2ccccc12</smiles> 
In their following work, Patil and coworkers applied very similar conditions to ortho-hydroxyaryl-enaminones to achieve their conversion into 3-alkynylchromones (equation 28) ${ }^{122}$. The procedure could be used with a variety of substituents on the aromatic ring, although lower yields were obtained with strongly electronwithdrawing groups. Based on few control experiments, Patil and coworkers proposed in this case a different mechanism, in which the initial gold-catalyzed alkynylation of the enaminone moiety is followed by cyclization via Michael addition followed by elimination of dimethylamine. While other silyl EBX reagents could be utilized instead of TIPS-EBX (3b), no reaction was observed with aryl substituted reagents.<smiles>[R]c1cccc(C(=O)/C=C/NC)c1O</smiles>
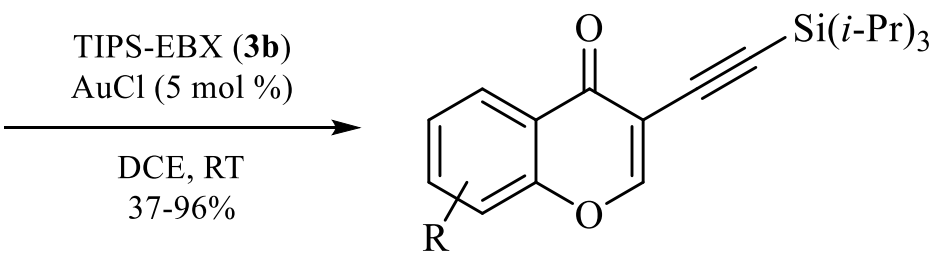<smiles>[R]c1ccc(O)c(C(=O)/C(C#C[AsH2+])=C\N([R17])C)c1</smiles>

As a further development, Waser and coworkers recently reported a convenient $\mathrm{Au}^{\mathrm{III}}$ - or $\mathrm{Pt}^{\mathrm{II}}$-catalyzed domino reaction to access 2,3-disubstituted 3-alkynyl benzofurans and benzothiophenes using TIPS-EBX (3b) and, respectively, ortho-ethnyl phenols and thiophenols ${ }^{123}$. The obtained products were then effectively transformed in furo- and thioacenes, molecules of great utility in the field of material science.

In a recent breakthrough, a cascade approach was used to overcome a significant drawback of most alkynylation reactions with benziodoxolones: During the alkynylation process, 2-iodobenzoic acid is generated as a stoichiometric by-product, leading to reduced atom economy. In 2016, Hari and Waser reasoned that a more efficient use of EBX reagents would be possible relying on the nucleophilic and electrophilic character simultaneously exhibited on a single carbon by metal carbenoids ${ }^{124}$. Indeed, they discovered that reacting $\alpha$ - 
diazo carbonyl compounds with ethynyl benziodoxolones in the presence of a $\mathrm{Cu}^{\mathrm{I}}$-catalyst resulted in the formation of the corresponding oxy-alkynylation products (Scheme 13). In this transformation, both the electrophilic alkynyl and the nucleophilic 2-iodobenzoyl moieties are transferred on the substrate, leading to high atom economy. The reaction, whose successful outcome depended on the use of di-imine ligand $\mathbf{6 6}$, worked well with silyl, aryl, and alkyl EBX reagents and a variety of diazo compounds, and could even be applied for the late-stage oxy-alkynylation of steroid-derived substrates. Importantly, when vinyl diazo substrates were submitted to the reaction conditions, only the corresponding vinylogous products were obtained as single geometric isomers.

For in-depth comprehension of the mechanism of this intriguing transformation, extensive investigations will be needed in the future. A plausible catalytic cycle was however proposed by Hari and Waser: they speculated that the formation of $\mathrm{Cu}^{\mathrm{I}}$-carbenoid $\mathbf{6 7}$ would be followed by the attack of the carboxylate group of EBX to generate organocopper species 68 (Scheme 14). The final product would then originate from the acetylene transfer onto the latter. Concerning this last step, the authors hypothesized three possible mechanistic scenarios: oxidative transfer of the acetylene group onto $\mathrm{Cu}^{\mathrm{I}}$ or nucleophilic attack of the $\mathrm{Cu}^{\mathrm{I}}$-ylide onto the $\alpha$ - or $\beta$-position of intermediate alkynyl iodonium salt $\mathbf{6 8}$. In the latter case, $\alpha$-elimination followed by a 1,2-shift would be needed for the formation of the product. As no 1,2-shift was evident from ${ }^{13} \mathrm{C}$-labeling experiment, this alternative was judged less probable.

\section{B. Alkynylation of Heteroatoms}

Owing to the electrophilic nature of alkynyliodonium salts, they have been used for the alkynylation of heteroatoms. In most cases, these reactions proceed via a conjugated addition/ $\alpha$-elimination/1,2-shift mechanism. This section describes alkynylations of oxygen, nitrogen, sulfur, phosphorous, and metal nucleophiles.

\section{Oxygen}

Alkynylation of oxygen with alkynyliodonium salts is often difficult and leads to decomposition. In 1985, Stang and coworkers reported a method for the synthesis of alkynyl tosylates from alkynyliodonium tosylates in the presence of copper triflate (equation 29) ${ }^{125,126}$. The authors also reported a method for preparing novel phosphate esters and alkynyl carboxylates from readily available alkynyliodonium tosylate precursors with diethyl phosphate and benzoate ions, respectively (equations 30 and 31) ${ }^{127}{ }^{128}$. In 1988, the same authors also reported the synthesis of acetylenic carboxylate from the reaction of $\mathrm{PhI}(\mathrm{OCOAr})_{2}$ with lithium acetylides (equation 32$)^{129}$. 

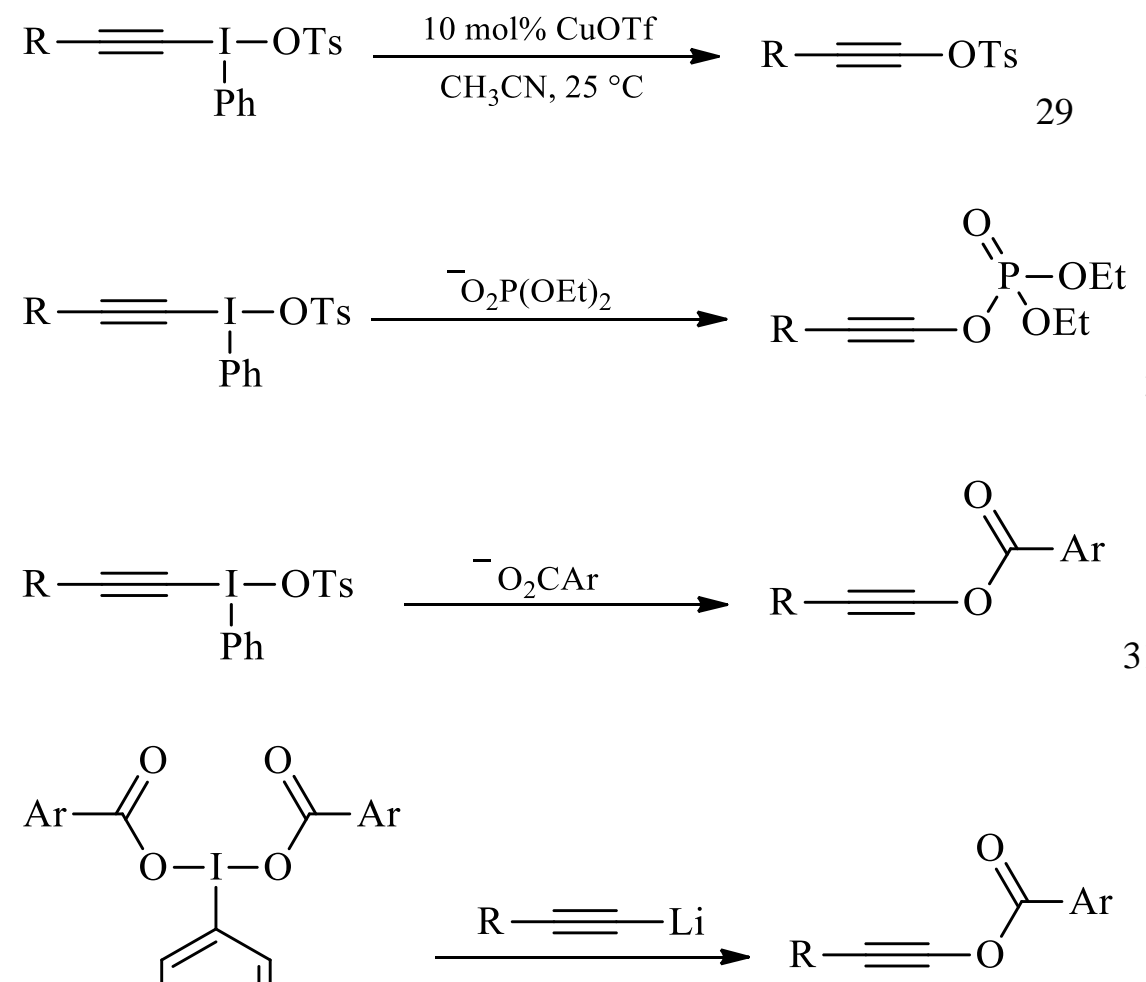

\section{Nitrogen}

The synthesis of ynamines, which have found widespread applications in organic synthesis, especially in metalcatalyzed cycloisomerization and cycloaddition reactions ${ }^{130}$, was reported later. In 1994, Stang and coworkers utilized alkynyliodonium salts for the synthesis of ynamines from lithium diphenylamide $\mathbf{6 9}$, but this transformation was limited to the synthesis of push-pull ynamines (equation 33$)^{131}$. Later, Feldman and coworkers ${ }^{132}$ and Witulsky and Stenge ${ }^{133}$ reported the synthesis of more stable ynamides $\mathbf{7 0}$ using alkynyliodonium salts (Scheme 15). There have been many other reports for the synthesis of ynamines based on the use of alkynyliodonium salts ${ }^{133-167}$. In general, the alkynylation of nitrogen nucleophiles works well for nitrogens bearing an electron-withdrawing group (products 71-75) and for heterocycles such as imidazole (product 76) ${ }^{146}$ or benzotriazole (product 77) ${ }^{165}$. The first synthesis of azidoacetylene $\mathbf{8 0}$ was reported by Banert and coworkers based on the reaction between an alkynyliodonium tetrafluoroborate $\mathbf{7 8}$ and azide phosphonium salt 79 (equation 34$)^{167}$.<smiles>CCOCC#CCCCCC#CC#CN(c1ccccc1)c1ccccc1</smiles> 
In 2013, Cossy and coworkers reported that the alkynylation of sulfonamides was possible with TMS-EBX (3a) (equation 35$)^{168}$. Interestingly, it was possible to alkynylate a tosyl amide in the presence of a carbamate. Later, in 2014, Ohno and coworkers also reported the synthesis of complex ynamide $\mathbf{8 2}$ based on the reaction between tosyl amide $\mathbf{8 1}$ and aryl EBX reagent $\mathbf{3 d}$ in the presence of a copper catalyst (equation 36) ${ }^{169}$. Alkynyl bromides were not successful in this reaction.
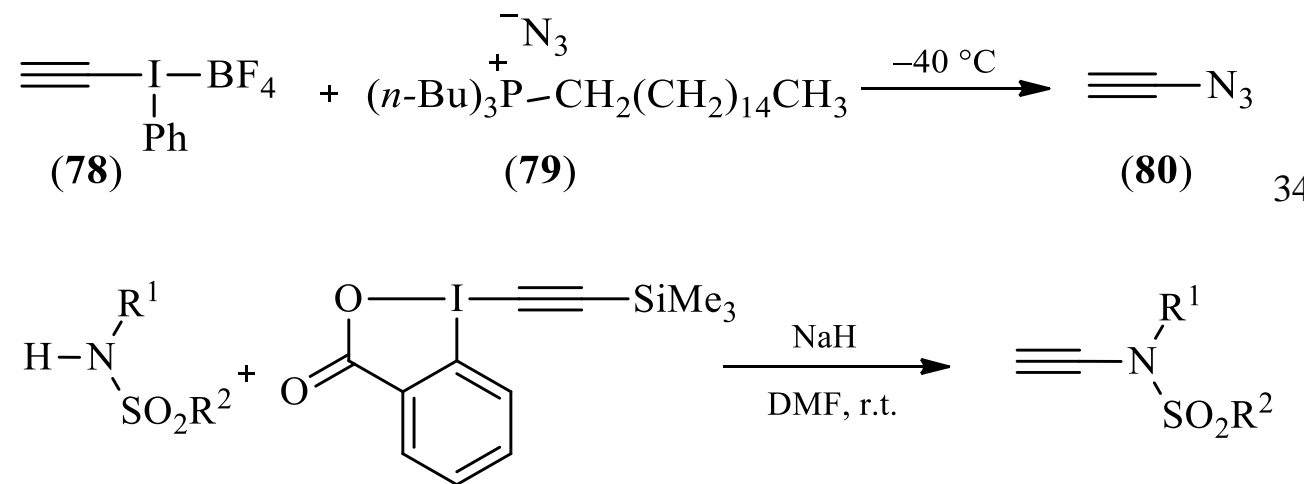

(3a)

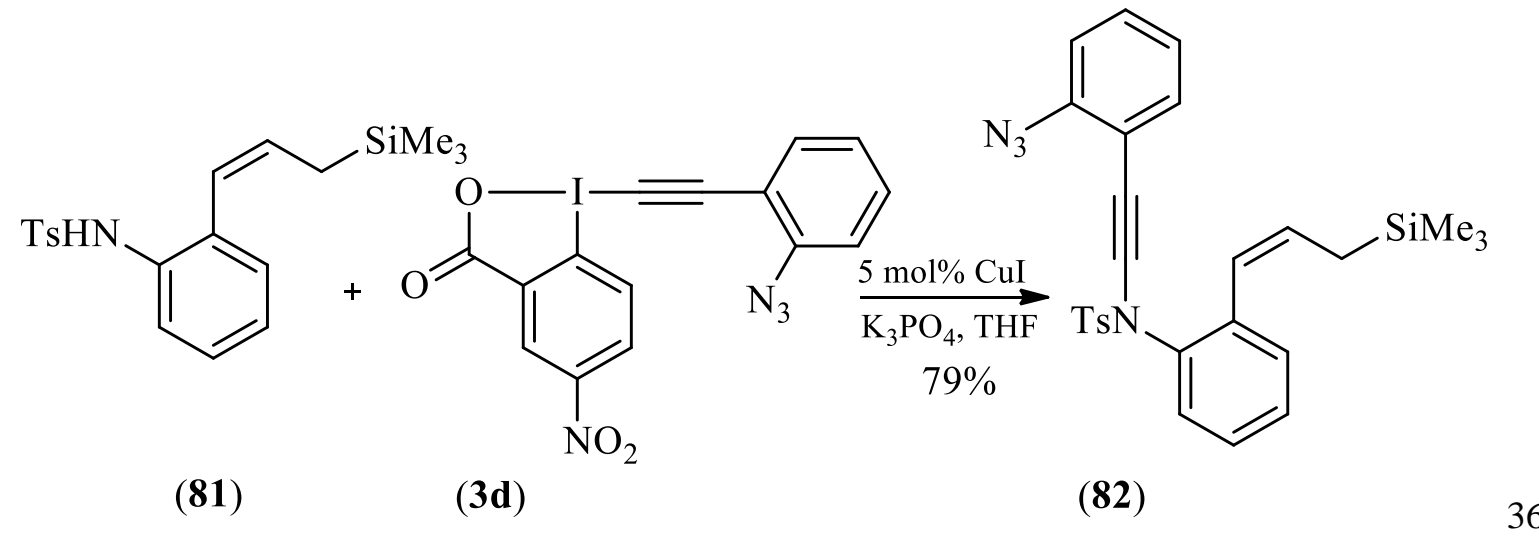

\section{Sulfur}

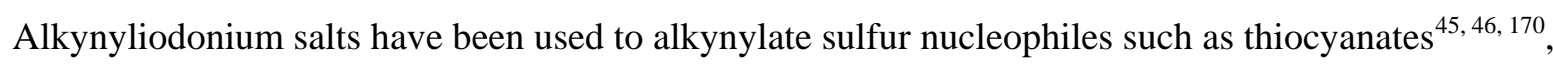
thiotosylates, ${ }^{171}$ and phosphordithioates (equation 37$)^{172}$. The alkynylation of thioamides is also possible, but in this case the alkynyl thioamidates spontaneously cyclized to give thiazoles (Scheme 16) ${ }^{173,174}$. The alkynylation of sulfinates ${ }^{175,176}$ with alkynyliodonium salts gives access to alkynyl sulfones (equation 38). Hamnett and Moran reported that the efficiency of the transfer of alkynyl groups to sulfinates could be increased by using 2iodoanisole compared to other iodoarenes as core of the hypervalent iodine reagent ${ }^{177}$. Ochiai and coworkers reported that alkynyliodonium salts could be used to access alkynylsulfonium, selenonium, and telluronium salts form the corresponding diphenyl chalcogens (equation 39) ${ }^{178}$. 


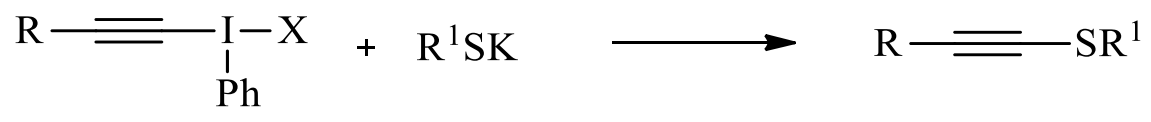

$\mathrm{X}=$ OTf, OTs

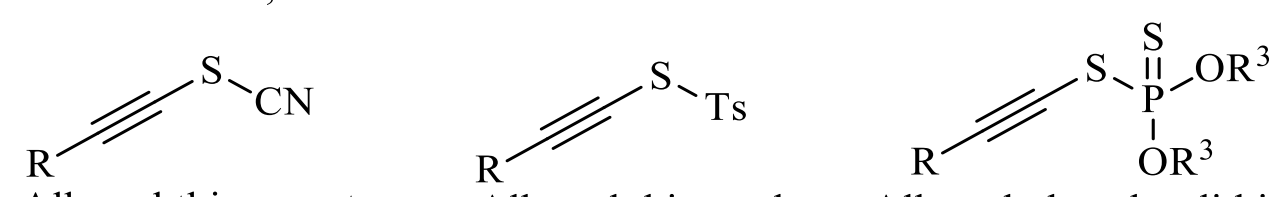

Alkynyl thiocyanates

Alkynyl thiotosylate Alkynyl phosphordithioates

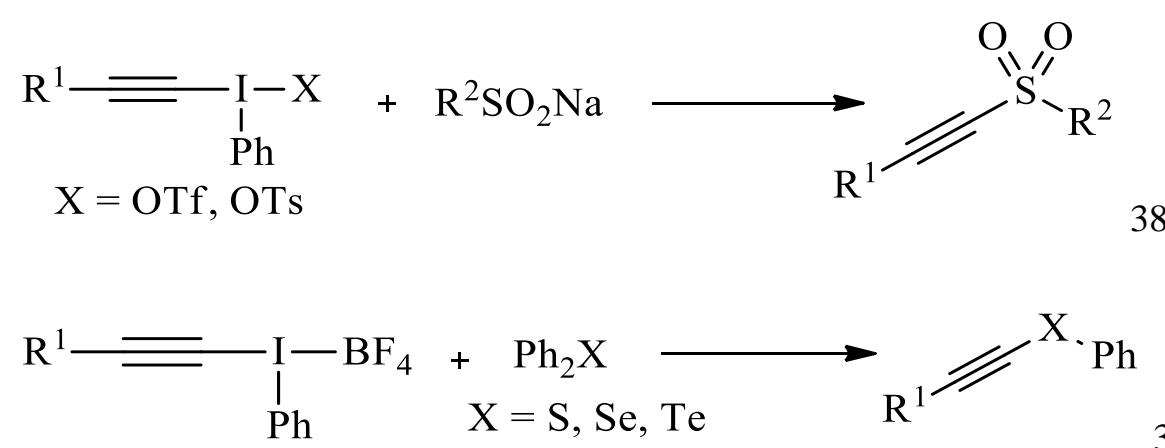

In 2015, Chen and Waser developed a new one-pot protocol for the preparation of arylalkynyl sulfones through the reaction of EBX, DABSO, and organomagnesium reagents (equation 40) ${ }^{179}$. Aryl iodides together with a palladium catalyst, DABSO, and EBX could be used for base sensitive substrates (equation 41).

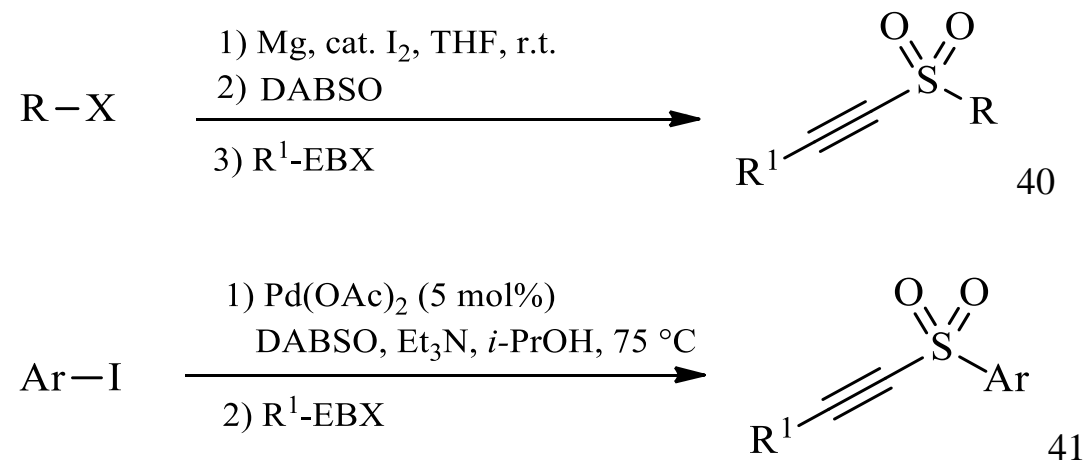

For decades, alkynyliodonium salts had been used only for the alkynylation of relatively electron-poor sulfur nucleophiles. This is probably because the oxidation of thiols to disulfides is the main reaction pathway for alkynyliodonium salts. In 2013, Frei and Waser developed a highly chemoselective alkynylation of thiols using TIPS-EBX (3b) (Scheme 17) ${ }^{180}$. The use of EBX reagents with tetramethylguanidine as base allowed to suppress the competing oxidation to form disulfides. The alkynylation reaction worked well for a broad range of thiols (products 83-85). Later, the same group reported the extension of the alkynylation reaction to the use of alkyl and aryl substituted EBX reagents (products $86-\mathbf{8 8})^{181}$. 
The authors proposed a mechanism for the alkynylation of thiols based on calculations (Scheme 18). A first possible pathway would be the attack of thiolate on the iodine atom of TIPS-EBX (3b) to give intermediate 89, which would then undergo reductive elimination to furnish the desired product 92 . However, intermediate 89 was not identified in the computational studies. A second possible mechanism would be the conjugate addition of thiolate on EBX to give intermediate 90, which would undergo $\alpha$-elimination followed by 1,2-shift to give the product 92. This pathway was observed in computational studies with a transition state energy of $23 \mathrm{kcal} \mathrm{mol}^{-1}$. In addition, another unprecedented pathway via three atom transition state $\mathbf{9 1}$ was found with a much lower energy of $10.8 \mathrm{kcal} \mathrm{mol}^{-1}$. Transition state 91 was distorted and showed a strong polarization. In 2015, they further reported a mechanism involving a four atom transition state $\mathbf{9 3}$ that was reached after initial sulfur-iodine interaction leading to $\beta$-addition ${ }^{182}$. This pathway was favored for electron donating groups such as alkyls, whereas $\alpha$-addition is favored for electron withdrawing groups. In the case of silicium and aryl substituents both mechanisms are possible.

In 2015, Adibekain and coworkers reported an efficient method for proteomic profiling of cysteine residues in complex proteomes and in living cells based on the alkynylation of cysteine in complex proteomes using azideEBX reagent (3e) (equation 42) ${ }^{183}$. The obtained products could be further functionalized with biotin alkyne via copper-catalyzed cycloaddition with azides. The authors further demonstrated the use of azide-functionalized alkynyl benziodoxolone for chemical proteomic applications by identifying one target of curcumin in HeLa cells. This new methodology using azide-EBX reagent $\mathbf{3 e}$ is complementary to established methods using iodoacetamide.

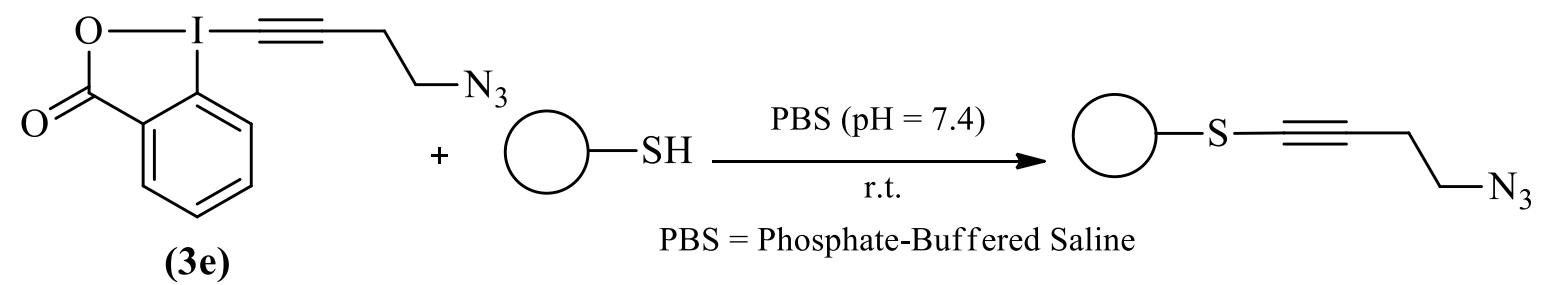

\section{Phosphorous}

The alkynylation of phosphorus nucleophiles has been less investigated compared to other nucleophiles. In 1987, Ochiai and coworkers first reported the alkynylation of triphenylphosphine with alkynyliodonium tetrafluoroborate salts under light irradiation (Scheme 19) ${ }^{184}$. In 1992, Stang and Crittell showed that light 
irradiation was not required if alkynyliodonium triflates were used instead of tetrafluoroborate salts ${ }^{185}$. Later, this methodology was extended to other nucleophiles such as triaryl or alkyl phosphines ${ }^{186,187}$. Lodaya and Koser also reported the synthesis of alkynylphosphonates from the reaction between alkynyliodonium tosylates and trialkyl phosphites (equation 43) ${ }^{188}$. Alternatively, alkynylphosphonates could also be obtained by the reaction of alkynyliodonium tosylates with sodium phosphonate salts ${ }^{189}$. In 2014 , Chen and Waser utilized the EBX reagents for the alkynylation of $H$-phosphites, -phosphinates and phosphine-oxides in the presence of base (Scheme 20$)^{190}$. Noteworthy, more complex substrates such as alkynylated phenyl AZT $H$-phosphinate 94, and $H$-(R)-BINOL phosphite derivative 95 were obtained in $70 \%$ and $86 \%$ yield, respectively.

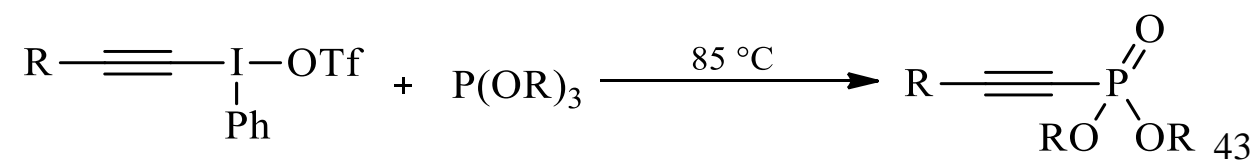

\section{Metals}

Transition-metal $\sigma$-alkynyl complexes have found applications in catalysis ${ }^{191}$ and in the preparation of materials ${ }^{192}$. The most common method to prepare alkynyl transition metal complexes involves the addition of a metal acetylide or terminal alkyne to a transition metal halide, $\mathrm{L}_{n} \mathrm{MX}(\mathrm{X}=\mathrm{C} 1, \mathrm{Br}, \mathrm{I})^{193}$. The reversed approach, the reaction of alkynyliodonium salts with electron-rich transition metals, gives an attractive alternative for the synthesis of transition-metal $\sigma$-alkynyl complexes. In 1990, Stang and Crittell first reported the alkynylation of Vaska complexes 96 and 97 with alkynyliodonium triflate in high isolated yields (equation 44) ${ }^{194}$. Later, thee group extended this methodology to the synthesis of bi- and trimetallic-acetylide complexes $\mathbf{1 0 0}$ and $\mathbf{1 0 1}$ by the reaction of Vaska complex 97)with bis and tris-alkynyliodonium salts (Figure 2) ${ }^{195,196}$. The reaction of platinum(0) complex 102 with alkynyliodonium triflate to give alkynylplatinum(II) complex was also reported by Stang and coworkers (equation 45$)^{197}$. The course of the reaction was influenced by the substituent on the alkyne: smaller R groups such as Me and $n$-Bu favor $\sigma$-alkynyl complex formation, whereas bulky $\mathrm{R}$ groups such as $t$-Bu and $\mathrm{Me}_{3} \mathrm{Si}$ favor $\eta^{3}$-complexation. 


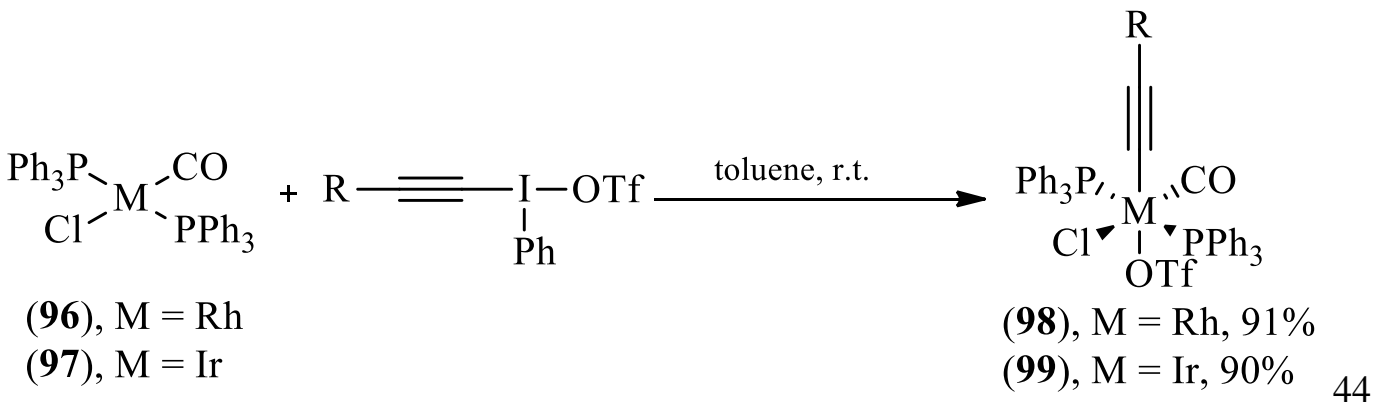

Canty and coworkers synthesized the alkynylplatinum(IV) complex 104 by the reaction of platinum(II) pincer complex 103 with alkynyliodonium salt in $91 \%$ yield (equation 46$)^{198}$. The exchange of triflate anion with iodide at the platinum(IV) center is facile, and the complex 105 was isolated in $91 \%$ yield. They further extended this method to access alkynylplatinum(IV) complexes 106 and 107 containing a bipyridine and a diphosphine ligand, respectively (Figure 3) ${ }^{199}$. Furthermore, alkynylpalladium(IV) complex 108 was also synthesized and characterized by the same group at low temperature ${ }^{199}$. Finally, in 2009, Canty and coworkers were able synthesize and characterize a rare platinum dimer 111 from the reaction of platinum(II) bipyridine complex $\mathbf{1 0 9}$ with alkynyliodonium triflate $\mathbf{1 1 0}$ followed by the treatment with $\mathrm{NaI}$ (equation 47$)^{200}$.<smiles>[R]C#C[I-](O)(c1ccccc1)c1ccccc1</smiles>

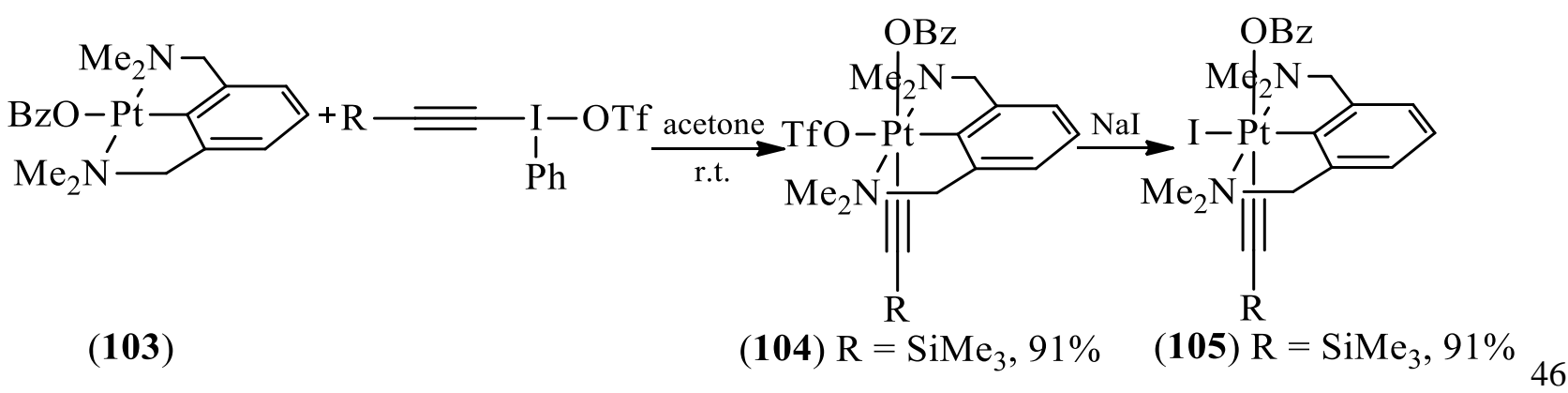


(c)

(109)
(111)

47

\section{ALKENYLATION REACTIONS}

A. Synthesis and Stability of Hypervalent Iodine Alkenylation Reagents

Alkenyl(aryl)iodonium salts have been used as alkenylating reagents in reactions with various nucleophiles because of the excellent leaving group ability of the aryl iodide group. Furthermore, they can be used as highly reactive alkenylating reagents in Heck- and Sonogashira-type reactions, and many other transition metalcatalyzed coupling reactions. The synthesis of alkenyl(aryl)iodonium salts was described in several reviews ${ }^{11,12 \text {, }}$ 29, 201, 202. The most general approach for the synthesis of tetrafluoroborate salts consists in reacting silyl alkenes with iodosylarenes followed by treatment with aqueous $\mathrm{NaBF}_{4}$ (equation 48, conditions A) ${ }^{203-205}$. An efficient alternative has also been developed based on borane-iodine(III) exchange of boronic acid with iodosylbenzene or (diacetoxyiodo)benzene in the presence of boron trifluoride etherate (equation 48, conditions B) ${ }^{206,207}$. A very mild method that allows the introduction of a broad range of substituents on the reagents can be achieved by reacting aryl(cyano)iodonium triflate with stannylated alkenes (equation 48, conditions C) $208,209$.

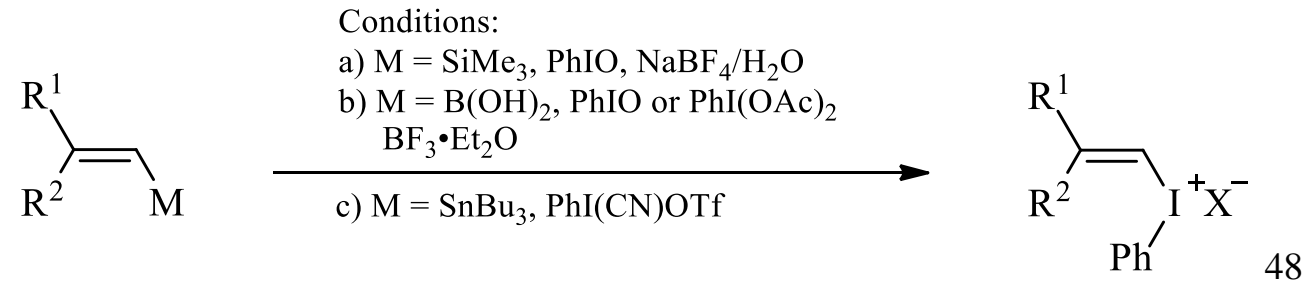


Fluorine bearing alkenyl(aryl)iodonium tetrafluoroborates were efficiently synthesized either by the treatment of terminal alkynes with $p$-iodotoluene difluoride in the presence of boron trifluoride etherate ${ }^{210}$ or by the reaction of alkynyl(aryl)iodonium salts with aqueous $\mathrm{HF}$ (equation 49 , conditions $\mathrm{A}$ and $\mathrm{B})^{211,212}$. The conjugate addition of sulfinic acid to alkynyl(aryl)iodonium salts provides $(Z)-(\beta$-sulfonylvinyl)iodonium salts stereoselectively (equation 50) ${ }^{213-215}$.
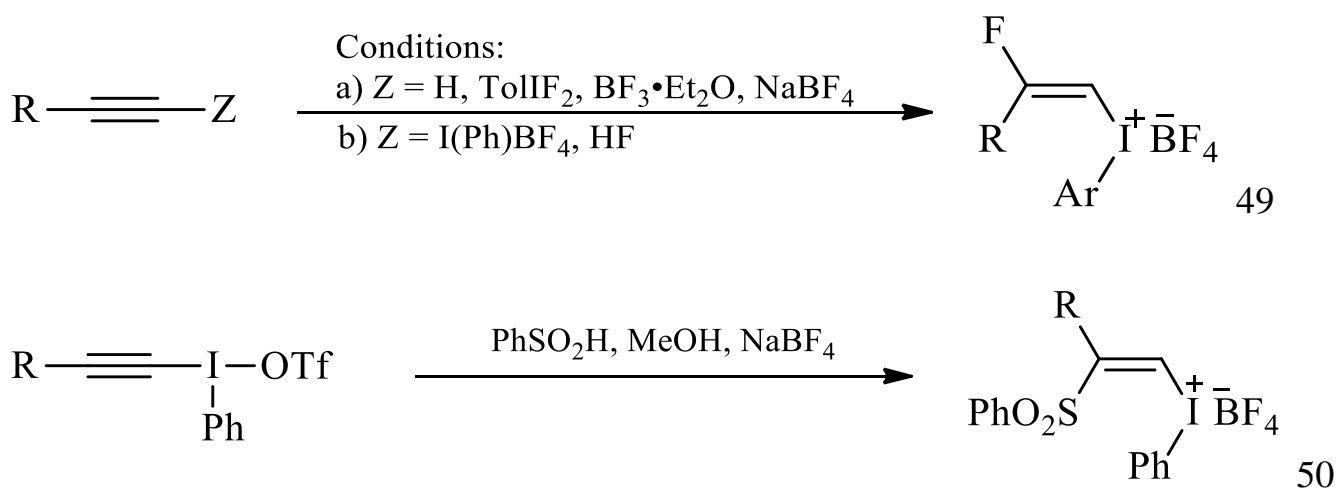

Azide bearing alkenylbenziodoxolone $\mathbf{1 1 2}$ could be efficiently synthesized by the reaction of alkynyl $(o-$ carboxyphenyl)iodonium triflate with azide ion (Scheme 21) ${ }^{216}$. More recently, Olofsson and coworkers reported the one-pot synthesis of alkenylbenziodoxolone reagents 113 from iodobenzoic acid (1), $m$-CPBA, and boronic acids (Scheme 21$)^{14}$. This method enables the access to alkyl, and aryl substituted reagents, providing a more convergent approach.

Yoshikai and coworkers reported the synthesis of $\beta$-oxyalkenylbenziodoxoles 114 from the reaction between

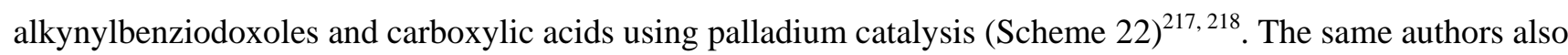
reported the synthesis of (alk-1-en-3-ynyl)benziodoxoles 115 by a Pd-catalyzed 2:1 coupling reaction between alkynylbenziodoxoles and carboxylic acids.

Alkenyl(aryl)iodonium salts are rather stable compounds, but they undergo thermal decomposition on heating ${ }^{11}$. For example, alkenyl bromide $\mathbf{1 1 7}$ and iodobenzene formed in a 1:1 ratio upon thermolysis of alkenyl(aryl)iodonium bromide 116 (equation 51) ${ }^{219}$. In addition, these salts also undergo solvolysis and fragmentation: the solvolysis of (4-tert-butylcyclohex-1-enyl)phenyliodonium tetrafluoroborate (118) in $\mathrm{MeOH}$ at $25{ }^{\circ} \mathrm{C}$ provided the solvolysis product $\mathbf{1 1 9}$, iodobenzene and coupling product $\mathbf{1 2 0}$ (equation 52) ${ }^{21}$. Fragmentations of alkenyl(aryl)iodonium salt $\mathbf{1 2 1}$ led to a mixture of products $\mathbf{1 2 3}$ and 124, which are formed via 1,2-migration on cationic intermediate $\mathbf{1 2 2}$, together with solvolysis products $\mathbf{1 2 5}$, and iodobenzene (equation 53$)^{220}$. 
<smiles>C=C[In](Br)c1ccccc1</smiles>

(116)
$\underset{-\mathrm{PhI}}{\stackrel{\Delta}{\longrightarrow}} \mathrm{H}_{2} \mathrm{C} \rightleftharpoons \mathrm{Br}$

(117)

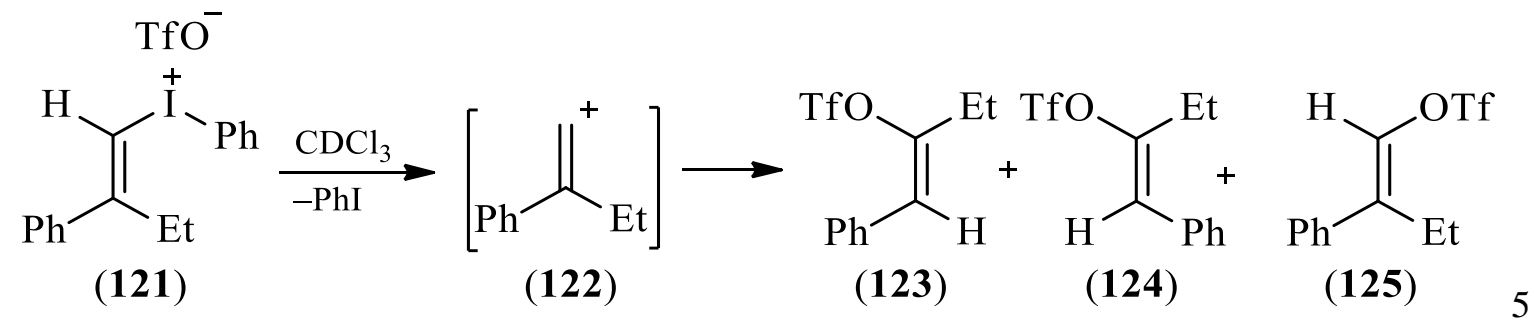

B. Alkenylation of Heteroatoms

Due to their excellent capability to produce alkenyl carbocations under very mild conditions, alkenyl(aryl)iodonium salts have been used as alkenylating reagents in reactions with various heteroatom nucleophiles including boron ${ }^{221,222}$, oxygen ${ }^{223-225}$, nitrogen ${ }^{203,224-226}$, halides ${ }^{203,213,224,225,227-229}$, silicon ${ }^{223}$, sulfur $^{203,213}$, and phosphorous ${ }^{225,230}$ (Scheme 23). Different mechanistic pathways such as $\mathrm{S}_{N} 1, \mathrm{~S}_{N} 2$, ligand coupling, and Michael addition-elimination have been proposed in alkenylation of heteroatom nucleophiles. The mechanistic aspects of these reactions have been discussed in several reviews ${ }^{231-233}$.

\section{Alkylidene Carbenes}

Owing to the high leaving ability of the aryliodide group, alkenyliodonium salts readily undergo $\alpha$ elimination to generate highly reactive alkylidene carbenes. In 1988, Ochiai and coworkers reported that alkenyl(aryl)iodonium tetrafluoroborate 126 undergoes 1,5-C-H insertion yielding cyclopentane $\mathbf{1 2 8}$ under mild conditions, which served as evidence for the generation of the corresponding alkylidene carbene $\mathbf{1 2 7}$ 
(equation 54$)^{234}$. They also reported the synthesis of 1-(phenylsulfonyl)cyclopentene $\mathbf{1 3 0}$ by treating $(Z)$ - $(\beta$ (phenylsulfonyl)alkenyl)iodonium tetrafluoroborate 129 with base (equation 55$)^{214}$. This procedure was also applied to hydroxy group bearing alkenyl(aryl)iodonium salt 131. Thus compound $\mathbf{1 3 1}$ underwent $\alpha$ elimination to produce a carbene, which then inserted into the $\mathrm{O}-\mathrm{H}$ bond to form 2,3-dihydrofuran derivative 132 (equation 56). A similar strategy was applied to the synthesis of fluorocyclopentenes 133-135 using fluoroalkylidenecarbenes by Hara and coworkers (equation 57) ${ }^{235}$.<smiles>CC(=C[I-])CC1CCCC1</smiles>

(126)<smiles>C=C(CC(C)CC1CC2C=C(C)CC2C1)CC1CCC(C)(C(C)C)C1</smiles>

(127)
(128), 84\% 54

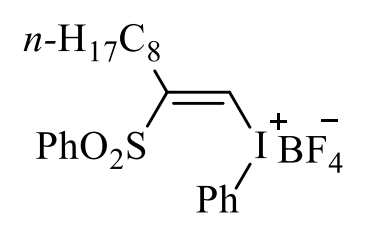

(129)

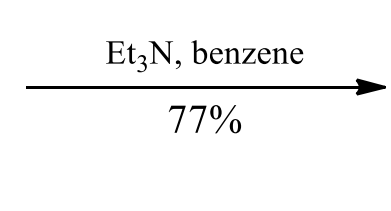

$\underset{\mathrm{Et}_{3} \mathrm{~N}, \text { benzene }}{61 \%}$<smiles>CCN(C)CCO</smiles>

(131)<smiles>O=S(=O)(O)C1=CC(Cc2ccccc2)CC1</smiles>

(130)<smiles>[R]CCCC(F)=C[I+]([Br+])c1ccccc1</smiles>

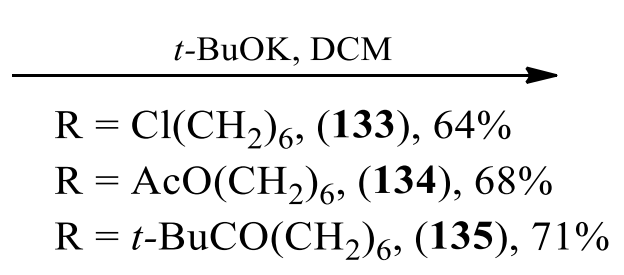<smiles>[R]C1C=C(F)CC1</smiles>

Ochiai and coworkers also demonstrated that alkylidene carbenes could be used for cyclopropanation reactions. The carbene generated from 136 via base-induced elimination readily underwent cycloaddition with styrene (137) under mild conditions to afford product $\mathbf{1 3 8}$ in $68 \%$ yield (equation 58 ) $^{236}$. 


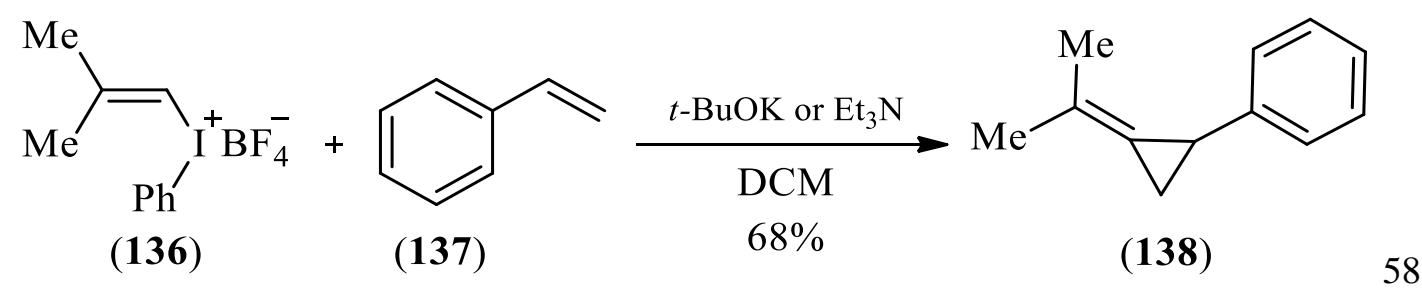

D. Alkenylation of C-Nucleophiles

In 1988, Ochiai and coworkers reported the alkenylation of the enolate $\mathbf{1 3 9}$ generated from 2-hexyl-1,3indanedione with cyclohexenyl(aryl)iodonium salt 118 to afford product 140 (equation 59) ${ }^{203}$. Later, they extended this method to the alkenylation of other enolates derived from various 1,3-dicarbonyl compounds ${ }^{237}$. Cyanation of alkenyl(aryl)iodonium salt $\mathbf{1 1 8}$ was also possible with cuprous potassium cyanide in DMF (equation 60) ${ }^{203}$.

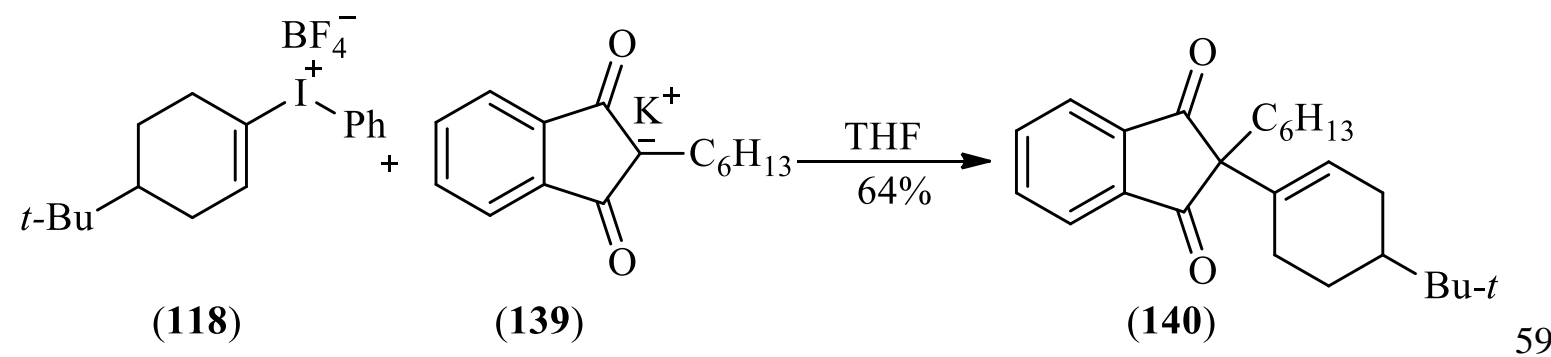<smiles>[B-][I+](c1ccccc1)c1ccc(C(Br)(Br)Br)cc1</smiles>

(118)<smiles>N#CC1=CCC(Br)CC1</smiles>

(141)

60

Recently, Olofsson and coworkers reported studies on the reactivity of an alkenylbenziodoxolone versus the corresponding acyclic alkenyl(aryl)iodonium salt in the alkenylation of nitrocyclohexane (142) ${ }^{14}$. They found that the use of cyclic reagent 113a resulted in favored formation of 1,1-disubstituted alkene 145, whereas 1,2disubstituted alkene 144 was the major product with acyclic reagent 143 (Scheme 24). 
Alkenylation of organometallic compounds such as organolithium and organomagnesium is not possible because they undergo oxidation in the presence of alkenyl(aryl)iodonium salts. On the other hand, these salts react smoothly with lithium organocuprates. The reaction was successful with alkyl ${ }^{203,226}$, aryl ${ }^{203,226}$, and alkynyl lithium cuprates ${ }^{238-240}$ to give aliphatic alkenes, aryl alkenes, and enynes (Scheme 25).

Unlike alkenyl halides, alkenyl(aryl)iodonium salts can readily lead to electrophilic aromatic substitution reactions due to their higher electrophilic nature. In 1986, Ochiai and coworkers reported the synthesis of 1,2dihydronaphthalene and 2H-chromene derivatives via cyclizations of alkenyl(aryl)iodonium tetrafluoroborates (equation 61$)^{241}$. This reaction proceeded under mild conditions without any catalyst. Intermolecular alkenylation of aromatic compounds could also be realized when 4-tert-butylcyclohexenyliodonium tetrafluoroborate (118) was heated in presence of excess of benzene at $80^{\circ} \mathrm{C}$ for $1 \mathrm{~h}$. The corresponding product 146 was isolated in $44 \%$ yield (equation 62 ).<smiles>[X]c1ccc([X]C(C)C(=O)OCC)c([R])c1</smiles><smiles>[13CH3]C1CC=C([I+]([18F])c2ccccc2)CC1</smiles>

(118)<smiles>Cc1ccccc1</smiles>

(146)

Alkenyl(aryl)iodonium salts have also found many applications in transition metal-catalyzed alkenylation reactions. Due to the high reactivity of these salts, the reaction conditions are milder than those used for alkenyl halides. In 1988, Ochiai and coworkers synthesized $\alpha, \beta$-unsaturated ester 147)from alkenyl(aryl)iodonium salt 118 by a Pd-catalyzed methoxycarbonylation reaction at $25^{\circ} \mathrm{C}$ (equation 63$)^{203}$. Kang and coworkers also reported the palladium-catalyzed alkoxycarbonylation of alkenyl(aryl)iodonium salt $\mathbf{1 4 3}$ at room temperature under $1 \mathrm{~atm}$ of CO to give $\mathbf{1 4 8}$ with complete retention of configuration (equation 64) ${ }^{242}$. In 2004, Hara and coworkers extended this methodology to the stereoselective synthesis of fluorine substituted $\alpha, \beta$-unsaturated esters from (Z)-2-fluoro-1-alkenyliodonium salts (equation 65$)^{243}$. The reaction proceeded under mild conditions and tolerated various functional groups including ketones, esters, and alkyl chains (products 149-151). 
<smiles>[13CH3]C1CC=C([I+]([18F])c2ccccc2)CC1</smiles>

(118)

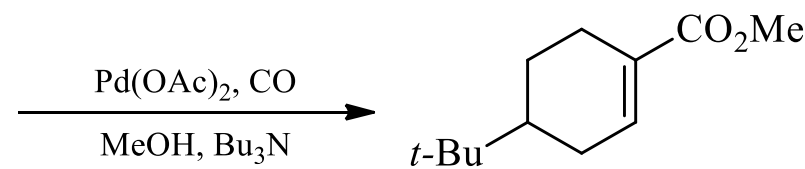<smiles></smiles>

(143)

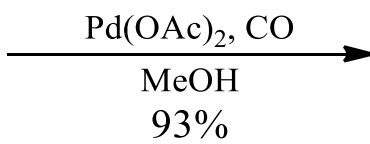

93\%<smiles>COC(=O)/C=C/c1ccccc1</smiles>

(148)
64<smiles></smiles>

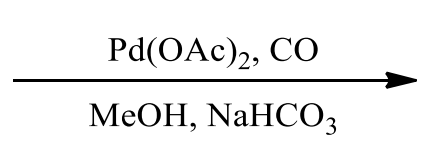<smiles>[R]C(F)=CC(=O)OC</smiles>

$$
\begin{aligned}
& \mathrm{R}=\mathrm{Cl}\left(\mathrm{CH}_{2}\right)_{9},(\mathbf{1 4 9}), 67 \% \\
& \mathrm{R}=i-\mathrm{PrO}_{2} \mathrm{C}\left(\mathrm{CH}_{2}\right)_{8},(\mathbf{1 5 0}), 66 \% \\
& \mathrm{R}=t-\mathrm{BuCO}\left(\mathrm{CH}_{2}\right)_{8},(\mathbf{1 5 1}), 68 \%
\end{aligned}
$$

Vinyl alkynyl ketones could be synthesized by the palladium-catalyzed carbonylation of alkenyl(aryl)iodonium salt 143 in the presence of terminal alkyne and copper iodide (equation 66) ${ }^{244}$. Carbonylation of alkenyl(aryl)iodonium salt $\mathbf{1 4 3}$ in the presence of a palladium catalyst with silyl alkenes and alkynes afforded the unsaturated ketones 152 and 153 (Scheme 26) ${ }^{245}$.<smiles>C(#C[P-]c1ccccc1)[P-]C#Cc1ccccc1</smiles>

(143)

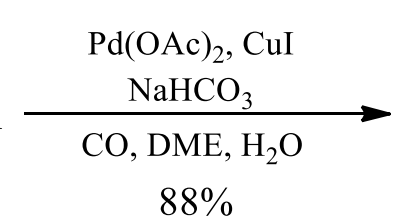

$88 \%$<smiles>O=C(C#Cc1ccccc1)/C=C/c1ccccc1</smiles>

(152)
66

Moriarty and coworkers reported a highly stereoselective palladium-catalyzed coupling reaction between alkenyl(aryl)iodonium salts and various olefins (equation 67) ${ }^{246}$. Unlike other Heck type reactions, this reaction proceeded at room temperature, thus preventing the polymerization of activated olefins such as acrolein. Palladium-catalyzed reaction of organic halides with allylic alcohols usually affords $\beta$-substituted ketones or aldehydes rather than the $\beta$-substituted allylic alcohols. Kang and coworkers took advantage of the high 
reactivity of alkenyl(aryl)iodonium salts to synthesize substituted allylic alcohols $\mathbf{1 5 4}$ and $\mathbf{1 5 5}$ by reacting alkenyl(aryl)iodonium tetrafluoroborate $\mathbf{1 4 3}$ with allylic alcohols in the presence of $\mathrm{Pd}(\mathrm{OAc})_{2}$ as catalyst

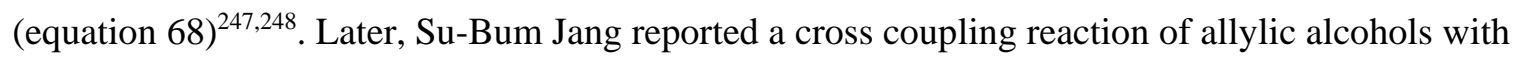
alkenyl(aryl)iodonium salts using a polymer-bound palladium catalyst. ${ }^{249}$

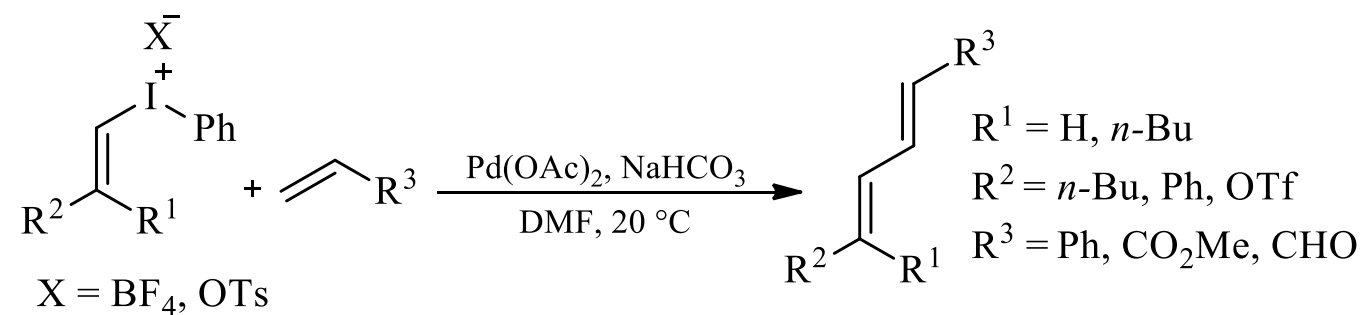

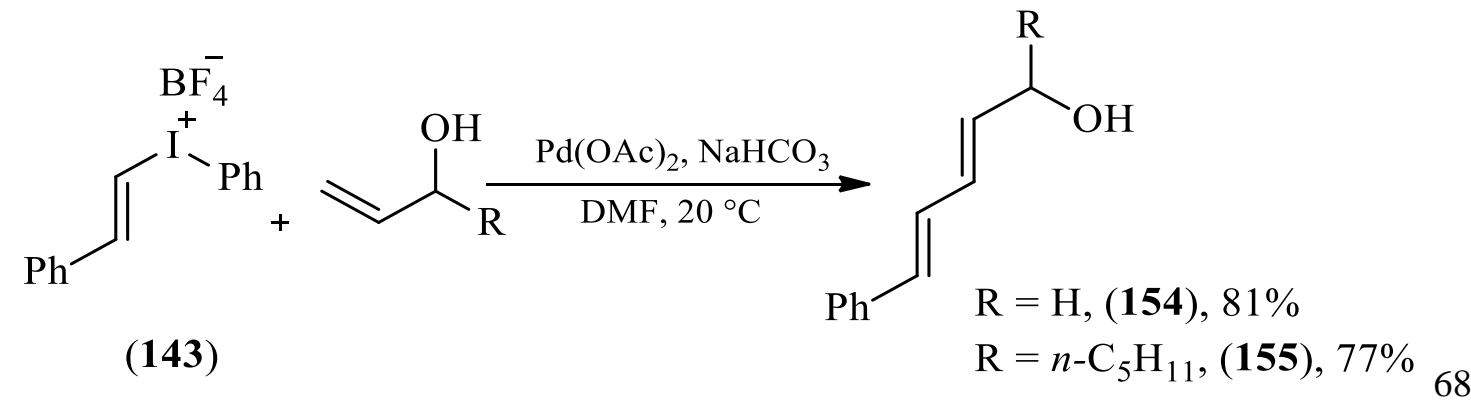

Later, the authors reported the palladium-catalyzed cross coupling of alkenylfluorosilanes promoted by fluoride ion with alkenyl(aryl)iodonium tetrafluoroborate $\mathbf{1 4 3}$ at room temperature (Scheme 27$)^{245}$. The palladiumcatalyzed cross-coupling reaction of alkenyl(aryl)iodonium salts with organoboron reagent was also achieved by Kang's group ${ }^{250}$. Furthermore, these salts undergo coupling reactions with alkynyl stannanes ${ }^{251}$, alkynylfluoromethylsilane ${ }^{245}$, and terminal alkynes ${ }^{252}$ to afford enynes (Scheme 28). Finally, Shibasaki and coworkers showed that the asymmetric alkenylation of 2,3-dihydrofuran (157) with alkenyl(aryl)iodonium tetrafluoroborate 156 was possible using $\mathrm{Pd}(\mathrm{OAc})_{2} /(R)$-BINAP (equation 69$)^{253}$.

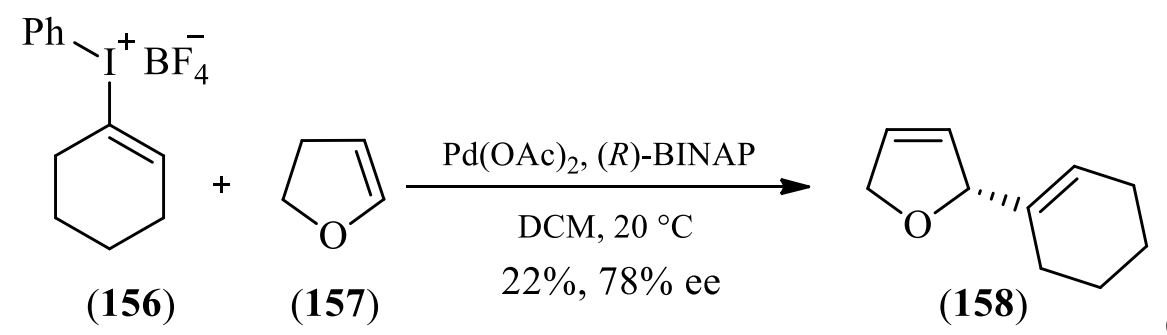


The enantioselective $\alpha$-alkenylation of aldehydes without racemization or olefin transposition is highly challenging. In 2012, Skucas and MacMillan reported a highly enantioselective method for the $\alpha$-alkenylation of aldehydes with alkenyl(aryl)iodonium salts using a synergy between copper and chiral amine catalysis (Scheme $29)^{254}$. The reaction tolerated a sterically $\beta$-branched aldehyde (product 160) and heteroatom functionalities (product 161). Electron-deficient and electron-neutral styrenes as well as alkylvinyl groups were efficiently transferred with high levels of selectivities (products 162 and 163). The authors hypothesized that oxidative addition of the alkenyl(aryl)iodonium salt to a $\mathrm{Cu}^{\mathrm{I}}$ catalyst generates an electrophilic alkenyl- $\mathrm{Cu}^{\mathrm{III}}$ species (Scheme 29). Addition of the enamine, which is generated by the condensation of the chiral amine catalyst 164 with the aldehyde, to the $\mathrm{Cu}^{\text {III }}$-alkenyl complex would deliver the enantioenriched $\alpha$-alkenylated aldehyde.

In 2016, Feng and coworkers reported a chiral Lewis acid catalyzed enantioselective $\alpha$-alkenylation of $\beta$-keto amides/esters with alkenyl(aryl)iodonium salts (Scheme 30$)^{255}$. This transformation provided an efficient access to all-carbon quaternary $\beta$-keto amides/esters in high yields and selectivities. A variety of indenone scaffolds were successfully used in this reaction to give the corresponding products in excellent yields and enantioselectivities (products 166 and 167). However, in the case of 1-tetralone derived $\beta$-ketoamide (product 168), lower reactivity and enantioselectivity was observed. Product 166 could be efficiently converted into $\alpha$ alkyl ketone 169 through reduction using $\mathrm{Pd} / \mathrm{C}, \mathrm{H}_{2}$.

In 2013, Gaunt and coworkers reported the endo-selective electrophilic carbofunctionalization of allylic amide

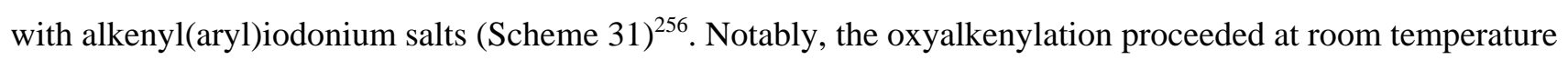
in contrast to the oxyarylation using diaryliodonium salts, which worked at $70{ }^{\circ} \mathrm{C}$, thus indicating the higher reactivity of alkenyl(aryl)iodonium salts in comparison to diaryliodonium salts. The oxyalkenylation reaction was suitable for a broad range of allylic amides and alkenyl(aryl)iodonium salts (products 170-172). The reaction was also efficient with an iso-propyl substituent at the allylic position (product 172). Interestingly, the alkenylation took place from the same face as the iso-propyl group to give the syn product, whereas the diastereoselectivity of the oxyalkenylation remained anti. Under the standard reaction conditions, the allylic amide $\mathbf{1 7 3}$ formed the exo product $\mathbf{1 7 5}$ in good yield, which supported the formation of a cationic intermediate during the reaction.

Later, Holt and Gaunt reported a copper-catalyzed oxyalkenylation of homoallylic carbamates with alkenyl(aryl)iodonium salts to form syn-1,3 carbonates in excellent yield and with very good selectivity (Scheme 32$)^{257}$. The reaction was applicable to a range of substituted homoallylic carbamates and alkenyl(aryl)iodonium salts. Notably, the diastereoselectivity was not affected by changing the steric demands of the substrate (compare products 176 and 177). In addition to primary homoallylic carbamates, the reaction worked well with substituents on the internal position of the carbon-carbon bond to form cyclic carbonate $\mathbf{1 7 8}$ 
containing a quaternary carbon atom. The obtained oxyalkenylated products can be used in an iterative process. The carbonate 181 was cleaved to the corresponding diol, which could be easily transformed into the carbamate 182, which then participated in a second iteration of oxyalkenylation to give the propionate stereotetrad $\mathbf{1 8 3}$ in good yield and selectivity. The authors proposed that the copper catalyzed oxy-alkenylation proceeds through a copper(III)-alkenyl species acting as an electrophile, which complexes the alkene and activates the carboncarbon double bond for an anti-attack by the pendant carbonyl group via a chair-like transition state $\mathbf{1 8 4}$ to form copper alkyl complex 185 (Scheme 33). Reductive elimination followed by hydrolysis then gives 1,3-syncarbonates.

In 2012, You and coworkers reported an efficient method to synthesize alkenyl substituted furoindolines via the $\mathrm{Cu}^{\mathrm{I}}$-catalyzed dearomative alkenylation of 2-substituted tryptophols (equation 70$)^{258}$. The authors found that alkenyl(aryl)iodonium salts displayed superior reactivity compared to diaryliodonium salts.

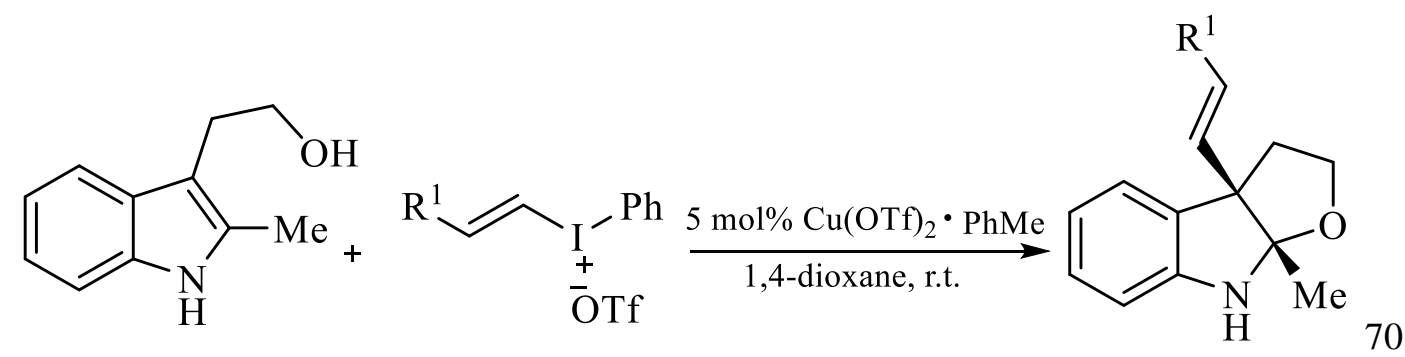

In 2014, Li and coworkers reported the alkenylation-carbocyclization of electron-deficient alkene $\mathbf{1 8 6}$ with alkenyliodonium salts, providing highly functionalized 3,3-disubstituted oxindoles (Scheme 34) ${ }^{259}$. Styrenyl and cyclohexyl substituted alkenyl groups were efficiently transferred (products $\mathbf{1 8 7}$ and 188) in 74\% and 60\% yield, respectively. Furthermore, the authors applied the alkenyl addition-cyclization method to accomplish the highly efficient and concise formal synthesis of $( \pm)$-physostigmine (190) and $( \pm)$-physovenine (191) in six steps in $41 \%$ and $36 \%$ overall yield, respectively.

In 2016, Liu and Wang reported the alkenylation of electron-deficient (hetero)arenes with alkenyl(aryl)iodonium salts (Scheme 35) ${ }^{260}$. Various (hetero)arenes such as nicotinonitrile, benzimidazole, oxazole, and pentafluorobenzene were efficiently alkenylated with styrenyl(phenyl)iodonium salt in good yields (products 192-195). The proposed mechanism of the reaction starts with selective $\mathrm{C}-\mathrm{H}$ deprotonative zincation followed by copper catalyzed carbon-carbon coupling reactions with styrenyl(phenyl)iodonium salts

\section{CONCLUSIONS}


The introduction of alkynes and alkenes as nucleophiles into electrophilic positions of molecules is currently the method of choice for the synthesis of alkynes and alkenes derivatives, but it limits the structural diversity and potential applications of these important classes of compounds. The excellent ability of hypervalent iodine reagents to act as one of the best electrophilic synthons of nucleophilic alkynes and alkenes have attracted strong interest since the mid-1980s. Their high reactivity and benign environmental character are attractive features, which enable challenging transformations without the need for high temperatures and excess of reagents. However, the use of alkynyliodonium salts as alkynylating reagents is limited due to their lower stability. Since 2009, more stable cyclic benziodoxol(on)e reagents have been identified as superior alternatives to alkynyliodonium salts in several transformations. In particular, recent developments in metal-free and metalcatalyzed alkynylations and alkenylations of carbon centered nucleophiles, radicals, and heteroatom nucleophiles have led to important progress in the area. The current intensive research in the field promises well for further progress and a broader use of these hypervalent iodine reagents in mainstream synthetic chemistry.

Despite significant achievements in alkynylation and alkenylation using hypervalent iodine reagents, there are still important limitations to address. The formation of iodoarenes as a stoichiometric byproduct makes largescale reactions less appealing. Therefore, the development of electrophilic alkynylations and alkenylations catalytic in hypervalent iodine reagents would be highly desirable. Furthermore, successful enantioselective processes have been very rare and more research is needed in this area.

\section{References}

1. F. Diederich, P. J. Stang and R. R. Tykwinski, Acetylene Chemistry: Chemistry, Biology and Material Science, Wiley-VCH, Weinheim, 2005.

2. B. M. Trost and A. H. Weiss, Adv. Synth. Catal., 351, 963 (2009).

3. R. Chinchilla and C. Najera, Chem. Soc. Rev., 40, 5084 (2011).

4. C.-Y. Ho, K. D. Schleicher, C.-W. Chan and T. F. Jamison, Synlett, 2009, 2565 (2009).

5. A. S. Dudnik and V. Gevorgyan, Angew. Chem., Int. Ed., 49, 2096 (2010).

6. J. P. Brand and J. Waser, Chem. Soc. Rev., 41, 4165 (2012).

7. S. Messaoudi, J.-D. Brion and M. Alami, Eur. J. Org. Chem., 2010, 6495 (2010).

8. A. Yoshimura and V. V. Zhdankin, Chem. Rev., 116, 3328 (2016).

9. F. M. Beringer and S. A. Galton, J. Org. Chem., 30, 1930 (1965).

10. V. V. Zhdankin and P. J. Stang, Tetrahedron, 54, 10927 (1998).

11. N. S. Pirkuliev, V. K. Brel and N. S. Zefirov, Russ. Chem. Rev., 69, 105 (2000).

12. M. S. Yusubov, A. V. Maskaev and V. V. Zhdankin, ARKIVOC, 370 (2011).

13. Y. Li, D. P. Hari, M. V. Vita and J. Waser, Angew. Chem., Int. Ed., 55, 4436 (2016).

14. E. Stridfeldt, A. Seemann, M. J. Bouma, C. Dey, A. Ertan and B. Olofsson, Chem.-Eur. J., 22, 16066 (2016).

15. A. S. Kende, P. Fludzinski and J. H. Hill, J. Am. Chem. Soc., 106, 3551 (1984).

16. R. L. Smorada and W. E. Truce, J. Org. Chem., 44, 3444 (1979).

17. J. Gong and P. L. Fuchs, J. Am. Chem. Soc., 118, 4486 (1996).

18. A.-P. Schaffner, V. Darmency and P. Renaud, Angew. Chem., Int. Ed., 45, 5847 (2006). 
19. J. L. García Ruano, J. Alemán, L. Marzo, C. Alvarado, M. Tortosa, S. Díaz-Tendero and A. Fraile, Angew. Chem., Int. Ed., 51, 2712 (2012).

20. J. L. García Ruano, J. Alemán, L. Marzo, C. Alvarado, M. Tortosa, S. Díaz-Tendero and A. Fraile, Chem.-Eur. J., 18, 8414 (2012).

21. T. Okuyama, T. Takino, T. Sueda and M. Ochiai, J. Am. Chem. Soc., 117, 3360 (1995).

22. M. Ochiai, T. Sueda, K. Miyamoto, P. Kiprof and V. V. Zhdankin, Angew. Chem., Int. Ed., 45, 8203 (2006).

23. P. K. Sajith and C. H. Suresh, Inorg. Chem., 52, 6046 (2013).

24. M. G. Moloney, J. T. Pinhey and E. G. Roche, Tetrahedron Lett., 27, 5025 (1986).

25. C. J. Parkinson, T. W. Hambley and J. T. Pinhey, J. Chem. Soc. Perkin Trans. 1, 1465 (1997).

26. R. L. Amey and J. C. Martin, J. Org. Chem., 44, 1779 (1979).

27. T.-Y. Sun, X. Wang, H. Geng, Y. Xie, Y.-D. Wu, X. Zhang and H. F. Schaefer, III, Chem. Commun., 52, 5371 (2016).

28. J. Waser, 'Alkynylation with Hypervalent lodine Reagents,' in Hypervalent lodine Chemistry (Ed.

T. Wirth) Topp. Curr. Chem., Springer International Publishing, Cham, 2016, pp. 187.

29. P. J. Stang, Angew. Chem., Int. Ed., 31, 274 (1992).

30. M. Ochiai, M. Kunishima, K. Sumi, Y. Nagao, E. Fujita, M. Arimoto and H. Yamaguchi, Tetrahedron Lett., 26, 4501 (1985).

31. T. Kitamura, M. Kotani and Y. Fujiwara, Synthesis (Stuttg), 1998, 1416 (1998).

32. P. J. Stang, A. M. Arif and C. M. Crittell, Angew. Chem., Int. Ed. Engl., 29, 287 (1990).

33. P. J. Stang, B. L. Williamson and V. V. Zhdankin, J. Am. Chem. Soc., 113, 5870 (1991).

34. M. J. Bouma and B. Olofsson, Chem.-Eur. J., 18, 14242 (2012).

35. V. V. Zhdankin, Curr. Org. Synth., 2, 121 (2005).

36. M. Ochiai, Y. Masaki and M. Shiro, J. Org. Chem., 56, 5511 (1991).

37. V. V. Zhdankin, C. J. Kuehl, A. P. Krasutsky, J. T. Bolz and A. J. Simonsen, J. Org. Chem., 61, 6547 (1996).

38. J. P. Brand and J. Waser, Synthesis (Stuttg), 44, 1155 (2012).

39. J. P. Brand, C. Chevalley, R. Scopelliti and J. Waser, Chem.-Eur. J., 18, 5655 (2012).

40. M. Ochiai, M. Kunishima, Y. Nagao, K. Fuji, M. Shiro and E. Fujita, J. Am. Chem. Soc., 108, 8281 (1986).

41. M. Ochiai, T. Ito, Y. Takaoka, Y. Masaki, M. Kunishima, S. Tani and Y. Nagao, J. Chem. Soc., Chem. Commun., 118 (1990).

42. M. D. Bachi, N. Bar-Ner, C. M. Crittell, P. J. Stang and B. L. Williamson, J. Org. Chem., 56, 3912 (1991).

43. M. D. Bachi, N. Bar-Ner, P. J. Stang and B. L. Williamson, J. Org. Chem., 58, 7923 (1993).

44. T. Suzuki, Y. Uozumi and M. Shibasaki, J. Chem. Soc., Chem. Commun., 1593 (1991).

45. T. Kitamura, K. Nagata and H. Taniguchi, Tetrahedron Lett., 36, 1081 (1995).

46. T. Kitamura, T. Fukuoka, L. Zheng, T. Fujimoto, H. Taniguchi and Y. Fujiwara, Bull. Chem. Soc. Jpn., 69, 2649 (1996).

47. A. Dhara, J. Weinmann, A.-M. Krause and F. Beuerle, Chem.-Eur. J., 22, 12473 (2016).

48. D. Fernández González, J. P. Brand and J. Waser, Chem.-Eur. J., 16, 9457 (2010).

49. D. Fernández González, J. P. Brand, R. Mondière and J. Waser, Adv. Synth. Catal., 355, 1631 (2013).

50. X. Wu, S. Shirakawa and K. Maruoka, Org. Biomol. Chem., 12, 5388 (2014).

51. M. V. Vita, P. Mieville and J. Waser, Org. Lett., 16, 5768 (2014).

52 H. Shi, L. Fang, C. Tan, L. Shi, W. Zhang, C. Li, T. Luo and Z. Yang, J. Am. Chem. Soc., 133, 14944 (2011).

53. R. Long, J. Huang, W. Shao, S. Liu, Y. Lan, J. Gong and Z. Yang, Nat. Commun., 5, 5707 (2014).

54. H. Shi, C. Tan, W. Zhang, Z. Zhang, R. Long, T. Luo and Z. Yang, Org. Lett., 17, 2342 (2015). 
55. J. Zhang, X. Wang, S. Li, D. Li, S. Liu, Y. Lan, J. Gong and Z. Yang, Chem.-Eur. J., 21, 12596 (2015).

56. C. Lv, X. Yan, Q. Tu, Y. Di, C. Yuan, X. Fang, Y. Ben-David, L. Xia, J. Gong, Y. Shen, et al., Angew. Chem., Int. Ed., 55, 7539 (2016).

57. B. T. Parr, C. Economou and S. B. Herzon, Nature, 525, 507 (2015).

58. M. Kamlar, I. Cisarova and J. Vesely, Org. Biomol. Chem., 13, 2884 (2015).

59. P. Finkbeiner, N. M. Weckenmann and B. J. Nachtsheim, Org. Lett., 16, 1326 (2014).

60. A. Utaka, L. N. Cavalcanti and L. F. Silva, Chem. Commun., 50, 3810 (2014).

61. Z. Wang, X. Li and Y. Huang, Angew. Chem., Int. Ed., 52, 14219 (2013).

62. Z. Wang, L. Li and Y. Huang, J. Am. Chem. Soc., 136, 12233 (2014).

63. J. P. Brand, J. Charpentier and J. Waser, Angew. Chem., Int. Ed., 48, 9346 (2009).

64. M. B. Hansen, F. Hubálek, T. Skrydstrup and T. Hoeg-Jensen, Chem.-Eur. J., 22, 1572 (2016).

65. G. L. Tolnai, J. P. Brand and J. Waser, Beilstein J. Org. Chem., 12, 745 (2016).

66. C. Huang, C. B. Wille, H. He, V. B. G. Reddy, R. P. Nargund, S. Lin and A. Palani, Tetrahedron Lett., 58, 1219 (2017).

67. J. P. Brand and J. Waser, Angew. Chem., Int. Ed., 49, 7304 (2010).

68. Y. Li, J. P. Brand and J. Waser, Angew. Chem., Int. Ed., 52, 6743 (2013).

69. Y. Li and J. Waser, Beilstein J. Org. Chem., 9, 1763 (2013).

70. A. Nierth and M. A. Marletta, Angew. Chem., Int. Ed., 53, 2611 (2014).

71. Y. Li, F. Xie and X. Li, J. Org. Chem., 81, 715 (2016).

72. A. C. Shaikh, D. R. Shinde and N. T. Patil, Org. Lett., 18, 1056 (2016).

73. J. P. Brand and J. Waser, Org. Lett., 14, 744 (2012).

74. A. Székely, Á. Péter, K. Aradi, G. L. Tolnai and Z. Novák, Org. Lett., 19, 954 (2017).

75. A. Ariafard, ACS Catal., 4, 2896 (2014).

76. G. L. Tolnai, S. Ganss, J. P. Brand and J. Waser, Org. Lett., 15, 112 (2013).

77. C. Feng and T.-P. Loh, Angew. Chem., Int. Ed., 53, 2722 (2014).

78. K. D. Collins, F. Lied and F. Glorius, Chem. Commun., 50, 4459 (2014).

79. F. Xie, Z. Qi, S. Yu and X. Li, J. Am. Chem. Soc., 136, 4780 (2014).

80. C. Feng, D. Feng, Y. Luo and T.-P. Loh, Org. Lett., 16, 5956 (2014).

81. C. Feng, D. Feng and T.-P. Loh, Chem. Commun., 50, 9865 (2014).

82. X.-F. Yang, X.-H. Hu, C. Feng and T.-P. Loh, Chem. Commun., 51, 2532 (2015).

83. N. Jin, C. Pan, H. Zhang, P. Xu, Y. Cheng and C. Zhu, Adv. Synth. Catal., 357, 1149 (2015).

84. Y. Wu, Y. Yang, B. Zhou and Y. Li, J. Org. Chem., 80, 1946 (2015).

85. G.-D. Tang, C.-L. Pan and F. Xie, Org. Biomol. Chem., 14, 2898 (2016).

86. J. Jeong, P. Patel, H. Hwang and S. Chang, Org. Lett., 16, 4598 (2014).

87. X. Zhang, Z. Qi, J. Gao and X. Li, Org. Biomol. Chem., 12, 9329 (2014).

88. B. Liu, X. Wang, Z. Ge and R. Li, Org. Biomol. Chem., 14, 2944 (2016).

89. D. Kang and S. Hong, Org. Lett., 17, 1938 (2015).

90. R. Boobalan, P. Gandeepan and C.-H. Cheng, Org. Lett., 18, 3314 (2016).

91. Z.-Z. Zhang, B. Liu, C.-Y. Wang and B.-F. Shi, Org. Lett., 17, 4094 (2015).

92. H. Wang, F. Xie, Z. Qi and X. Li, Org. Lett., 17, 920 (2015).

93. W. Ai, Y. Wu, H. Tang, X. Yang, Y. Yang, Y. Li and B. Zhou, Chem. Commun., 51, 7871 (2015).

94. P. Finkbeiner, U. Kloeckner and B. J. Nachtsheim, Angew. Chem., Int. Ed., 54, 4949 (2015).

95. L. D. Caspers, P. Finkbeiner and B. J. Nachtsheim, Chem.-Eur. J., 23, 2748 (2017).

96. R.-Y. Zhang, L.-Y. Xi, L. Zhang, S. Liang, S.-Y. Chen and X.-Q. Yu, RSC Adv., 4, 54349 (2014).

97. Z.-F. Cheng, Y.-S. Feng, C. Rong, T. Xu, P.-F. Wang, J. Xu, J.-J. Dai and H.-J. Xu, Green Chem., 18, 4185 (2016).

98. X. Liu, L. Yu, M. Luo, J. Zhu and W. Wei, Chem.-Eur. J., 21, 8745 (2015).

99. R.-Y. Zhang, L.-Y. Xi, L. Zhang, S.-Y. Chen and X.-Q. Yu, Tetrahedron, 71, 6176 (2015). 
100. X.-H. Ouyang, R.-J. Song, C.-Y. Wang, Y. Yang and J.-H. Li, Chem. Commun., 51, 14497 (2015).

101. X. Liu, Z. Wang, X. Cheng and C. Li, J. Am. Chem. Soc., 134, 14330 (2012).

102. F. Chen and A. S. K. Hashmi, Org. Lett., 18, 2880 (2016).

103. X. Li, S. Li, S. Sun, F. Yang, W. Zhu, Y. Zhu, Y. Wu and Y. Wu, Adv. Synth. Catal., 358, 1699 (2016).

104. H. Wang, L. Guo, S. Wang and X.-H. Duan, Org. Lett., 17, 3054 (2015).

105. P.-F. Wang, Y.-S. Feng, Z.-F. Cheng, Q.-M. Wu, G.-Y. Wang, L.-L. Liu, J.-J. Dai, J. Xu and H.-J. $\mathrm{Xu}$, J. Org. Chem., 80, 9314 (2015).

106. L. Wang and J. Liu, Eur. J. Org. Chem., 2016, 1813 (2016).

107. H. Huang, G. Zhang, L. Gong, S. Zhang and Y. Chen, J. Am. Chem. Soc., 136, 2280 (2014).

108. H. Huang, G. Zhang and Y. Chen, Angew. Chem., Int. Ed., 54, 7872 (2015).

109. Q.-Q. Zhou, W. Guo, W. Ding, X. Wu, X. Chen, L.-Q. Lu and W.-J. Xiao, Angew. Chem., Int. Ed., 54, 11196 (2015).

110. F. Le Vaillant, T. Courant and J. Waser, Angew. Chem., Int. Ed., 54, 11200 (2015).

111. C. Yang, J.-D. Yang, Y.-H. Li, X. Li and J.-P. Cheng, J. Org. Chem., 81, 12357 (2016).

112. F. Le Vaillant, M. D. Wodrich and J. Waser, Chem. Sci., 8, 1790 (2017).

113. S. Wang, L. Guo, H. Wang and X.-H. Duan, Org. Lett., 17, 4798 (2015).

114. R.-Y. Zhang, L.-Y. Xi, L. Shi, X.-Z. Zhang, S.-Y. Chen and X.-Q. Yu, Org. Lett., 18, 4024 (2016).

115. K. Jia, F. Zhang, H. Huang and Y. Chen, J. Am. Chem. Soc., 138, 1514 (2016).

116. K. Jia, Y. Pan and Y. Chen, Angew. Chem., Int. Ed., 56, 2478 (2017).

117. S. Nicolai, S. Erard, D. F. González and J. Waser, Org. Lett., 12, 384 (2010).

118. S. Nicolai, C. Piemontesi and J. Waser, Angew. Chem., Int. Ed., 50, 4680 (2011).

119. J. P. Brand, C. Chevalley and J. Waser, Beilstein J. Org. Chem., 7, 565 (2011).

120. Y. Li and J. Waser, Angew. Chem., Int. Ed., 54, 5438 (2015).

121. P. S. Shinde, A. C. Shaikh and N. T. Patil, Chem. Commun., 52, 8152 (2016).

122. M. O. Akram, S. Bera and N. T. Patil, Chem. Commun., 52, 12306 (2016).

123. Y. Li, G. Gryn'ova, F. Saenz, X. Jeanbourquin, K. Sivula, C. Corminboeuf and J. Waser, Chem.-Eur. J., 23, 8058 (2017).

124. D. P. Hari and J. Waser, J. Am. Chem. Soc., 138, 2190 (2016).

125. P. J. Stang and B. W. Surber, J. Am. Chem. Soc., 107, 1452 (1985).

126. P. J. Stang, B. W. Surber, Z. C. Chen, K. A. Roberts and A. G. Anderson, J. Am. Chem. Soc., 109, 228 (1987).

127. P. J. Stang, M. Boehshar and J. Lin, J. Am. Chem. Soc., 108, 7832 (1986).

128. P. J. Stang, T. Kitamura, M. Boehshar and H. Wingert, J. Am. Chem. Soc., 111, 2225 (1989).

129. P. J. Stang, M. Boehshar, H. Wingert and T. Kitamura, J. Am. Chem. Soc., 110, 3272 (1988).

130. G. Evano, A. Coste and K. Jouvin, Angew. Chem., Int. Ed., 49, 2840 (2010).

131. P. Murch, B. L. Williamson and P. J. Stang, Synthesis (Stuttg), 1255 (1994).

132. K. S. Feldman, M. M. Bruendl, K. Schildknegt and A. C. Bohnstedt, J. Org. Chem., 61, 5440

(1996).

133. B. Witulski and T. Stengel, Angew. Chem., Int. Ed., 37, 489 (1998).

134. B. Witulski and T. Stengel, Angew. Chem., Int. Ed., 38, 2426 (1999).

135. J. D. Rainier and J. E. Imbriglio, Org. Lett., 1, 2037 (1999).

136. B. Witulski, T. Stengel and J. M. Fernández-Hernández, Chem. Commun., 36, 1965 (2000).

137. J. D. Rainier and J. E. Imbriglio, J. Org. Chem., 65, 7272 (2000).

138. B. Witulski and M. Gößmann, Synlett, 1793 (2000).

139. B. Witulski, N. Buschmann and U. Bergsträßer, Tetrahedron, 56, 8473 (2000).

140. B. Witulski and C. Alayrac, Angew. Chem., Int. Ed., 41, 3281 (2002).

141. G. Domínguez, L. Casarrubios, J. Rodríguez-Noriega and J. Pérez-Castells, Helv. Chim. Acta, 85, 2856 (2002). 
142. F. Denonne, P. Seiler and F. Diederich, Helv. Chim. Acta, 86, 3096 (2003).

143. F. Marion, C. Courillon and M. Malacria, Org. Lett., 5, 5095 (2003).

144. I. Bernhard, Synlett, 2003, 708 (2003).

145. S. Couty, B. Liégault, C. Meyer and J. Cossy, Org. Lett., 6, 2511 (2004).

146. S. M. Kerwin and A. Nadipuram, Synlett, 2004, 1404 (2004).

147. M. Klein and B. König, Tetrahedron, 60, 1087 (2004).

148. M. F. Martínez-Esperón, D. Rodríguez, L. Castedo and C. Saá, Org. Lett., 7, 2213 (2005).

149. K. Tanaka, K. Takeishi and K. Noguchi, J. Am. Chem. Soc., 128, 4586 (2006).

150. S. Couty, B. Liegault, C. Meyer and J. Cossy, Tetrahedron, 62, 3882 (2006).

151. A. K. Nadipuram and S. M. Kerwin, Tetrahedron, 62, 3798 (2006).

152. M. F. Martínez-Esperón, D. Rodríguez, L. Castedo and C. Saá, Tetrahedron, 62, 3843 (2006).

153. S. Couty, C. Meyer and J. Cossy, Tetrahedron Lett., 47, 767 (2006).

154. A. K. Nadipuram and S. M. Kerwin, Tetrahedron Lett., 47, 353 (2006).

155. A. S. K. Hashmi, R. Salathé and W. Frey, Synlett, 2007, 1763 (2007).

156. K. Tanaka and K. Takeishi, Synthesis (Stuttg), 2007, 2920 (2007).

157. A. S. K. Hashmi, M. Rudolph, J. W. Bats, W. Frey, F. Rominger and T. Oeser, Chem.-Eur. J., 14, 6672 (2008).

158 M. F. Martínez-Esperón, D. Rodríguez, L. Castedo and C. Saá, Tetrahedron, 64, 3674 (2008).

159 A. S. Hashmi, S. Pankajakshan, M. Rudolph, E. Enns, T. Bander, F. Rominger and W. Frey,

Adv. Synth. Catal., 351, 2855 (2009).

160. P. Garcia, S. Moulin, Y. Mielo, D. Leboeuf, V. Gandon, C. Aubert and M. Malacria, Chem.-Eur. J., 15, 2129 (2009).

161. S. Couty, C. Meyer and J. Cossy, Tetrahedron, 65, 1809 (2009).

162. B. Witulski, T. Schweikert, D. Schollmeyer and N. A. Nemkovich, Chem. Commun. (Camb.), 46, 2953 (2010).

163. F. Nissen, V. Richard, C. Alayrac and B. Witulski, Chem. Commun. (Camb.), 47, 6656 (2011).

164. F. Nissen and H. Detert, Eur. J. Org. Chem., 2011, 2845 (2011).

165. T. Kitamura, M. H. Morshed, S. Tsukada, Y. Miyazaki, N. Iguchi and D. Inoue, J. Org. Chem., 76, 8117 (2011).

166. S. Balieu, K. Toutah, L. Carro, L. M. Chamoreau, H. Rousselière and C. Courillon, Tetrahedron Lett., 52, 2876 (2011).

167. K. Banert, R. Arnold, M. Hagedorn, P. Thoss and A. A. Auer, Angew. Chem., Int. Ed., 51, 7515 (2012).

168. T. Aubineau, J. Cossy, W. Chen, D. Li, J. Dou, Z. Terashita and T. Naka, Chem. Commun., 49, 3303 (2013).

169. Y. Tokimizu, S. Oishi, N. Fujii and H. Ohno, Org. Lett., 16, 3138 (2014).

170. D. R. Fischer, B. L. Williamson and P. J. Stang, Synlett, 1992, 535 (1992).

171. B. L. Williamson, P. Murch, D. R. Fischer and P. J. Stang, Synlett, 1993, 858 (1993).

172. Z. Liu and Z. Chen, J. Org. Chem., 58, 1924 (1993).

173. P. Wipf and S. Venkatraman, J. Org. Chem., 61, 8004 (1996).

174. K. Miyamoto, Y. Nishi and M. Ochiai, Angew. Chem., Int. Ed., 44, 6896 (2005).

175. R. R. Tykwinski, B. L. Williamson, D. R. Fischer, P. J. Stang and A. M. Arif, J. Org. Chem., 58, 5235 (1993).

176. Z.-D. Liu and Z.-C. Chen, Synth. Commun., 22, 1997 (1992).

177. D. J. Hamnett and W. J. Moran, Org. Biomol. Chem., 12, 4156 (2014).

178. M. Ochiai, T. Nagaoka, T. Sueda, J. Yan, D.-W. Chen and K. Miyamoto, Org. Biomol. Chem., 1, 1517 (2003).

179. C. C. Chen and J. Waser, Org. Lett., 17, 736 (2015).

180. R. Frei and J. Waser, J. Am. Chem. Soc., 135, 9620 (2013).

181. R. Frei, M. D. Wodrich, D. P. Hari, P.-A. Borin, C. Chauvier and J. Waser, J. Am. Chem. Soc., 136, 16563 (2014). 
182. M. D. Wodrich, P. Caramenti and J. Waser, Org. Lett., 18, 60 (2016).

183. D. Abegg, R. Frei, L. Cerato, D. P. Hari, C. Wang, J. Waser and A. Adibekian, Angew. Chem., Int. Ed., 54, 10852 (2015).

184. M. Ochiai, M. Kunishima, Y. Nagao, K. Fuji and E. Fujita, J. Chem. Soc., Chem. Commun., 1987, (1708).

185. P. J. Stang and C. M. Crittell, J. Org. Chem., 57, 4305 (1992).

186. P. J. Stang, R. Tykwinski and V. V. Zhdankin, J. Org. Chem., 57, 1861 (1992).

187. K. K. Laali, M. Regitz, M. Birkel, P. J. Stang and C. M. Crittell, J. Org. Chem., 58, 4105 (1993).

188. J. S. Lodaya and G. F. Koser, J. Org. Chem., 55, 1513 (1990).

189. J.-L. Zhang and Z.-C. Chen, Synth. Commun., 28, 175 (1998).

190. C. C. Chen and J. Waser, Chem. Commun., 50, 12923 (2014).

191. D. H. Berry and R. Eisenberg, Organometallics, 6, 1796 (1987).

192. K. Sonogashira, K. Ohga, S. Takahashi and N. Hagihara, J. Organomet. Chem., 188, 237

(1980).

193. E. Sappa, A. Tiripicchio and P. Braunstein, Coord. Chem. Rev., 65, 219 (1985).

194. P. J. Stang and C. M. Crittell, Organometallics, 9, 3191 (1990).

195. R. R. Tykwinski and P. J. Stang, Organometallics, 13, 3203 (1994).

196. P. J. Stang and R. Tykwinski, J. Am. Chem. Soc., 114, 4411 (1992).

197. P. J. Stang, C. M. Crittell and A. M. Arif, Organometallics, 12, 4799 (1993).

198. A. J. Canty, T. Rodemann, B. W. Skelton and A. H. White, Inorg. Chem. Commun., 8, 55 (2005).

199. A. J. Canty, T. Rodemann, B. W. Skelton and A. H. White, Organometallics, 25, 3996 (2006).

200. A. J. Canty, M. G. Gardiner, R. C. Jones, T. Rodemann and M. Sharma, J. Am. Chem. Soc.,

131,7236 (2009).

201. P. J. Stang and V. V. Zhdankin, Chem. Rev., 96, 1123 (1996).

202. V. V. Zhdankin and P. J. Stang, Chem. Rev., 108, 5299 (2008).

203. M. Ochiai, K. Sumi, Y. Takaoka, M. Kunishima, Y. Nagao, M. Shiro and E. Fujita, Tetrahedron, 44, 4095 (1988).

204. D. W. Chen and M. Ochiai, J. Org. Chem., 64, 6804 (1999).

205. M. Ochiai, T. Sueda, R. Noda and M. Shiro, J. Org. Chem., 64, 8563 (1999).

206. M. Ochiai, M. Toyonari, T. Nagaoka, D. W. Chen and M. Kida, Tetrahedron Lett., 38, 6709

(1997).

207. M. Fujita, H. J. Lee and T. Okuyama, Org. Lett., 8, 1399 (2006).

208. R. J. Hinkle and P. J. Stang, Synthesis (Stuttg), 313 (1994).

209. A. J. Mcneil, R. J. Hinkle, E. A. Rouse, Q. A. Thomas and D. B. Thomas, J. Org. Chem., 16, 5556 (2001).

210. M. Yoshida, K. Kawakami and S. Hara, Synthesis (Stuttg), 2004, 2821 (2004).

211. M. Yoshida and S. Hara, Org. Lett., 5, 573 (2003).

212. M. Yoshida, A. Komata and S. Hara, Tetrahedron, 62, 8636 (2006).

213. M. Ochiai, K. Oshima and Y. Masaki, Tetrahedron Lett., 32, 7711 (1991).

214. M. Ochiai, M. Kunishima, S. Tani and Y. Nagao, J. Am. Chem. Soc., 113, 3135 (1991).

215. E. Zawia, D. J. Hamnett and W. J. Moran, J. Org. Chem., 82, 3960 (2017).

216. T. Kitamura, T. Fukuoka and Y. Fujiwara, Synlett, 659 (1996).

217. J. Wu, X. Deng, H. Hirao and N. Yoshikai, J. Am. Chem. Soc., 138, 9105 (2016).

218. J. Wu, K. Xu, H. Hirao and N. Yoshikai, Chem.-Eur. J., 23, 1521 (2017).

219. A. N. Nesmeyanov, T. P. Tolstaya and A. V. Petrakov, Dokl. Akad. Nauk. SSSR, 197, 1337

(1971).

220. R. J. Hinkle and D. B. Thomas, J. Org. Chem., 62, 7534 (1997).

221. T. Guan, M. Yoshida and S. Hara, J. Org. Chem., 72, 9617 (2007).

222. S. Hara, T. Guan and M. Yoshida, Org. Lett., 5, 5 (2006).

223. T. Kitamura and P. J. Stang, Tetrahedron Lett., 29, 1887 (1988).

224. I. Papoutsis, S. Spyroudis and A. Varvoglis, Tetrahedron, 54, 1005 (1998). 
225. N. S. Zefirov, A. S. Koz, T. Kasumov, K. A. Potekhin, V. D. Sorokin, V. K. Brel, E. V. Abramkin, V. V. Zhdankin and P. J. Stang, J. Org. Chem., 57, 2433 (1992).

226. M. Ochiai, K. Sumi, Y. Nagao and E. Fujita, Tetrahedron Lett., 26, 2351 (1985).

227. M. Ishikura and M. Terashima, J. Chem. Soc., Chem. Commun., 727 (1989).

228. M. Terashima and M. Isikura, Heterocycles, 27, 2619 (1988).

229. M. Ochiai, K. Oshima and Y. Masaki, J. Am. Chem. Soc., 113, 7059 (1991).

230. S. Thielges, P. Bisseret and J. Eustache, Org. Lett., 7, 681 (2005).

231. M. Ochiai, J. Organomet. Chem., 611, 494 (2000).

232. T. Okuyama, Acc. Chem. Res., 35, 12 (2002).

233. T. Okuyama and G. Lodder, Adv. Phys. Org. Chem., 37, 1 (2002).

234. M. Ochiai, Y. Takaoka and Y. Nagao, J. Am. Chem. Soc., 110, 6565 (1988).

235. T. Guan, K. Takemura, H. Senboku, M. Yoshida and S. Hara, Tetrahedron Lett., 49, 76 (2008).

236. M. Ochiai, T. Sueda, K. Uemura and Y. Masaki, J. Org. Chem., 60, 2624 (1995).

237. M. Ochiai, T. Shu, T. Nagaoka and Y. Kitagawa, J. Org. Chem., 62, 2130 (1997).

238. P. J. Stang, A. Schwarz, T. Blume and V. V. Zhdankin, Tetrahedron Lett., 33, 6759 (1992).

239. P. J. Stang, T. Blume and V. V. Zhdankin, Synthesis (Stuttg), 35 (1993).

240. J. H. Ryan and P. J. Stang, J. Org. Chem., 61, 6162 (1996).

241. M. Ochiai, Y. Takaoka, K. Sumi and Y. Nagao, J. Chem. Soc., Chem. Commun., 1382 (1986).

242. S.-K. Kang, T. Yamaguchi, P.-S. Ho, W.-Y. Kim and H.-C. Ryu, J. Chem. Soc., Perkin Trans. 1, 841 (1998).

243. M. Yoshida, A. Komata and S. Hara, J. Fluorine Chem., 125, 527 (2004).

244. S.-K. Kang and K.-H. Lim, Synthesis (Stuttg), 874 (1997).

245. S.-K. Kang, T. Yamaguchi, R.-K. Hong, T.-H. Kim and S.-J. Pyun, Tetrahedron, 53, 3027 (1997).

246. R. M. Moriarty, W. R. Epa and A. K. Awasthi, J. Am. Chem. Soc., 113, 6315 (1991).

247. S.-K. Kang, K.-Y. Jung, C.-H. Park and S.-B. Jang, Tetrahedron Lett., 36, 8047 (1995).

248. S.-K. Kang, H.-W. Lee, S.-B. Jang, T.-H. Kim and S.-J. Pyun, J. Org. Chem., 61, 2604 (1996).

249. S.-B. Jang, Tetrahedron Lett., 38, 4421 (1997).

250. S.-K. Kang, H.-W. Lee, S.-B. Jang and P.-S. Ho, J. Org. Chem., 61, 4720 (1996).

251. R. J. Hinkle, G. T. Poulter and P. J. Stang, J. Am. Chem. Soc., 115, 11626 (1993).

252. N. S. Pirguliyev, V. K. Brel, N. S. Zefirov and P. J. Stang, Tetrahedron, 55, 12377 (1999).

253. Y. Kurihara, M. Sodeoka and M. Shibasaki, Chem. Pharm. Bull., 42, 2357 (1994).

254. E. Skucas and D. W. C. MacMillan, J. Am. Chem. Soc., 134, 9090 (2012).

255. J. Guo, L. Lin, Y. Liu, X. Li, X. Liu and X. Feng, Org. Lett., 18, 5540 (2016).

256. E. Cahard, N. Bremeyer and M. J. Gaunt, Angew. Chem., Int. Ed., 52, 9284 (2013).

257. D. Holt and M. J. Gaunt, Angew. Chem., Int. Ed., 54, 7857 (2015).

258. C. Liu, W. Zhang, L.-X. Dai and S.-L. You, Org. Lett., 14, 4525 (2012).

259. B. Zhou, W. Hou, Y. Yang, H. Feng and Y. Li, Org. Lett., 16, 1322 (2014).

260. C. Liu and Q. Wang, Org. Lett., 18, 5118 (2016).

\section{FIGURE 1}

Photoredox catalysts used in alkynylation reactions with EBX reagents.

\section{FIGURE 2}

Bi- and trimetallic-acetylide complexes $\mathbf{1 0 0}$ and $\mathbf{1 0 1}$. 


\section{FIGURE 3}

Alkynylplatinum(IV) and palladium(IV) complexes 106-108.

\section{SCHEME 1}

Nucleophilic versus electrophilic alkynylation/vinylation reactions and used hypervalent iodine reagents.

\section{SCHEME 2}

Synthesis of alkynyl hypervalent iodine reagents.

\section{SCHEME 3}

a-Alkynylation of diketones with iodonium salts and proposed mechanism.

\section{SCHEME 4}

Synthesis of TBTQ 19 using alkynyl iodonium salt 17.

\section{SCHEME 5}

Reactions of TIPS-EBX (3b) with aldehydes under combined gold/enamine catalysis.

\section{SCHEME 6}

Use of TIPS-EBX (3b) in the gold-catalyzed alkynylation of (hetero)arenes.

\section{SCHEME 7}

Revised mechanism for the gold-catalyzed alkynylation of indole $\mathbf{3 5 .}$

\section{SCHEME 8}

Proposed mechanisms for the $\mathrm{Rh}^{\mathrm{III}}$-catalyzed $\mathrm{C}\left(\mathrm{sp}^{2}\right)-\mathrm{H}$ alkynylation.

\section{SCHEME 9}

Radical alkynylation of aliphatic $\mathrm{C}-\mathrm{H}$ bonds and aldehydes with EBX reagents.

\section{SCHEME 10}

Photoredox catalyzed decarboxylative alkynylation of carboxylic acids.

\section{SCHEME 11}

Putative catalytic cycle for the photoredox catalyzed decarboxylative alkynylation.

\section{SCHEME 12}

Proposed mechanism for the alkynylation via photoredox catalyzed cleavage of tertiary alcohols. 
SCHEME 13

$\mathrm{Cu}^{\mathrm{I}}$-catalyzed oxy-alkynylation of diazo compounds with $\mathrm{EBX}$ reagents.

SCHEME 14

Speculative mechanism for the oxy-alkynylation of diazo compounds with EBX reagents.

SCHEME 15

Alkynylation of nitrogen bearing electron-withdrawing groups and heterocycles.

SCHEME 16

Alkynylation of thioamides.

SCHEME 17

Alkynylation of thiols.

SCHEME 18

Mechanism for the alkynylation of thiols.

SCHEME 19

Alkynylation of triphenylphosphine.

SCHEME 20

Alkynylation of phosphorous nucleophiles with EBX reagents.

\section{SCHEME 21}

Synthesis of vinylbenziodoxolones $\mathbf{1 1 2}$ and $\mathbf{1 1 3}$.

SCHEME 22

Palladium-catalyzed synthesis of vinylbenziodoxolones 114 and 115.

\section{SCHEME 23}

Alkenylation of heteroatoms.

\section{SCHEME 24}

Alkenylation of nitrocyclohexane (142) with cyclic and acyclic alkenyl hypervalent iodine reagents 113a and 143. 
SCHEME 25

Alkenylation of lithium cuprates.

SCHEME 26

Carbonylation of alkenyl(aryl)iodonium 143 with silyl alkenes and alkynes.

\section{SCHEME 27}

Synthesis of dienes from alkenyl(aryl)iodonium salts.

\section{SCHEME 28}

Synthesis of enynes from alkenyl(aryl)iodonium salts.

\section{SCHEME 29}

Enantioselective $\alpha$-alkenylation of aldehydes and proposed mechanism.

\section{SCHEME 30}

Enantioselective $\alpha$-alkenylation of $\beta$-keto amides/esters.

\section{SCHEME 31}

Electrophilic carbofunctionalization of allylic amides with alkenyl(aryl)iodonium salts.

\section{SCHEME 32}

Copper-catalyzed oxyalkenylation of homoallylic carbamates.

\section{SCHEME 33}

Proposed mechanism of the copper-catalyzed oxyalkenylation of homoallylic carbamates.

\section{SCHEME 34}

Copper-catalyzed alkenylation-carbocyclization of electron-deficient alkenes.

\section{SCHEME 35}

Alkenylation of electron-deficient (hetero)arenes. 